\title{
The role of lipocalin-2 in age-related macular degeneration (AMD)
}

\author{
Sayan Ghosh ${ }^{1} \cdot$ Nadezda Stepicheva $^{1} \cdot$ Meysam Yazdankhah ${ }^{1} \cdot$ Peng Shang ${ }^{1} \cdot$ Alan M. Watson $^{2} \cdot$ Stacey Hose $^{1}$. \\ Haitao Liu ${ }^{1}$. Joseph Weiss ${ }^{1} \cdot$ J. Samuel Zigler $\mathrm{Jr}^{3} \cdot$ Mallika Valapala ${ }^{4}$. Simon C. Watkins ${ }^{2} \cdot$ Debasish Sinha ${ }^{1,3,5}$
}

Received: 4 December 2019 / Revised: 4 December 2019 / Accepted: 10 December 2019 / Published online: 4 January 2020

(c) Springer Nature Switzerland AG 2020

\begin{abstract}
Lipocalins are a family of secreted adipokines which play important roles in various biological processes. Lipocalin-2 (LCN2) has been shown to be involved in acute and chronic inflammation. This particular protein is critical in the pathogenesis of several diseases including cancer, diabetes, obesity, and multiple sclerosis. Herein, we discuss the general molecular basis for the involvement of LCN-2 in acute infections and chronic disease progression and also ascertain the probable role of LCN-2 in ocular diseases, particularly in age-related macular degeneration (AMD). We elaborate on the signaling cascades which trigger LCN-2 upregulation in AMD and suggest therapeutic strategies for targeting such pathways.
\end{abstract}

Keywords Lipocalin-2 (LCN-2) · Age-related macular degeneration (AMD) $\cdot$ Inflammation $\cdot$ AKT2 signaling $\cdot$ Retinal degeneration

\section{Structure and expression of lipocalin-2 (LCN-2)}

Lipocalin-2 (LCN-2) is a member of the broader lipocalin family of proteins that includes over 20 soluble proteins, most of which are extracellular [1-5]. This family

Electronic supplementary material The online version of this article (https://doi.org/10.1007/s00018-019-03423-8) contains supplementary material, which is available to authorized users.

Sayan Ghosh

sayang@pitt.edu

Debasish Sinha

Debasish@pitt.edu

1 Department of Ophthalmology, Children's Hospital of University of Pittsburgh School of Medicine, One Children's Hospital Drive, 4401 Penn Avenue, Pittsburgh, PA 15224, USA

2 Center for Biologic Imaging and Department of Cellular Biology, University of Pittsburgh School of Medicine, Pittsburgh, PA, USA

3 Department of Ophthalmology, Johns Hopkins University School of Medicine, Baltimore, MD, USA

4 School of Optometry, Indiana University, Bloomington, IN, USA

5 Department of Ophthalmology, Cell Biology and Developmental Biology, Children's Hospital of University of Pittsburgh School of Medicine, One Children's Hospital Drive, 4401 Penn Avenue, Pittsburgh, PA 15224, USA is evolutionarily conserved and found in different lineages from bacteria to plants, invertebrates, and vertebrates (Fig. 1) [5]. Lipocalins have a three-dimensional structure (lipocalin domain) in which eight $\beta$-strands form a symmetrical $\beta$-barrel fold with a cylindrical shape (Fig. 2) [4]. The $\beta$-barrel structure provides a hydrophobic cavity to bind to a variety of lipophilic ligands [2], including retinoic acid, progesterone, prostaglandin, and fatty acids [6].

The lipocalin proteins play an important role in a variety of biological processes, including retinoid binding, immune responses, olfaction, pheromone transport, and prostaglandin synthesis [2,7]. Additionally, lipocalins are associated with the regulation of critical cellular processes, such as proliferation, differentiation [8], migration [9], and survival [10]. Some lipocalins can be used as biomarkers of human diseases including tear lipocalin (TLC) [7], orosomucoid ( $\alpha 1$-acid glycoprotein), protein HC ( $\alpha 1$-microglobulin), apolipoprotein $\mathrm{D}$, retinol-binding protein, complement $\mathrm{C} 8$, and prostaglandin D synthase [11].

In the human genome, the LCN-2 gene was found in a cluster of three lipocalins, on the long arm of chromosome 9 (syntenic to a region on mouse chromosome 4) [12]. Human LCN-2 protein was initially identified as a $25-\mathrm{kD}$ a protein from phorbol myristate acetate (PMA) stimulated neutrophils that were bound to gelatinase [13-15]. Polyclonal antibodies raised against neutrophil gelatinase not only recognized gelatinase, but also this $25-\mathrm{kDa}$ protein [14]. There 

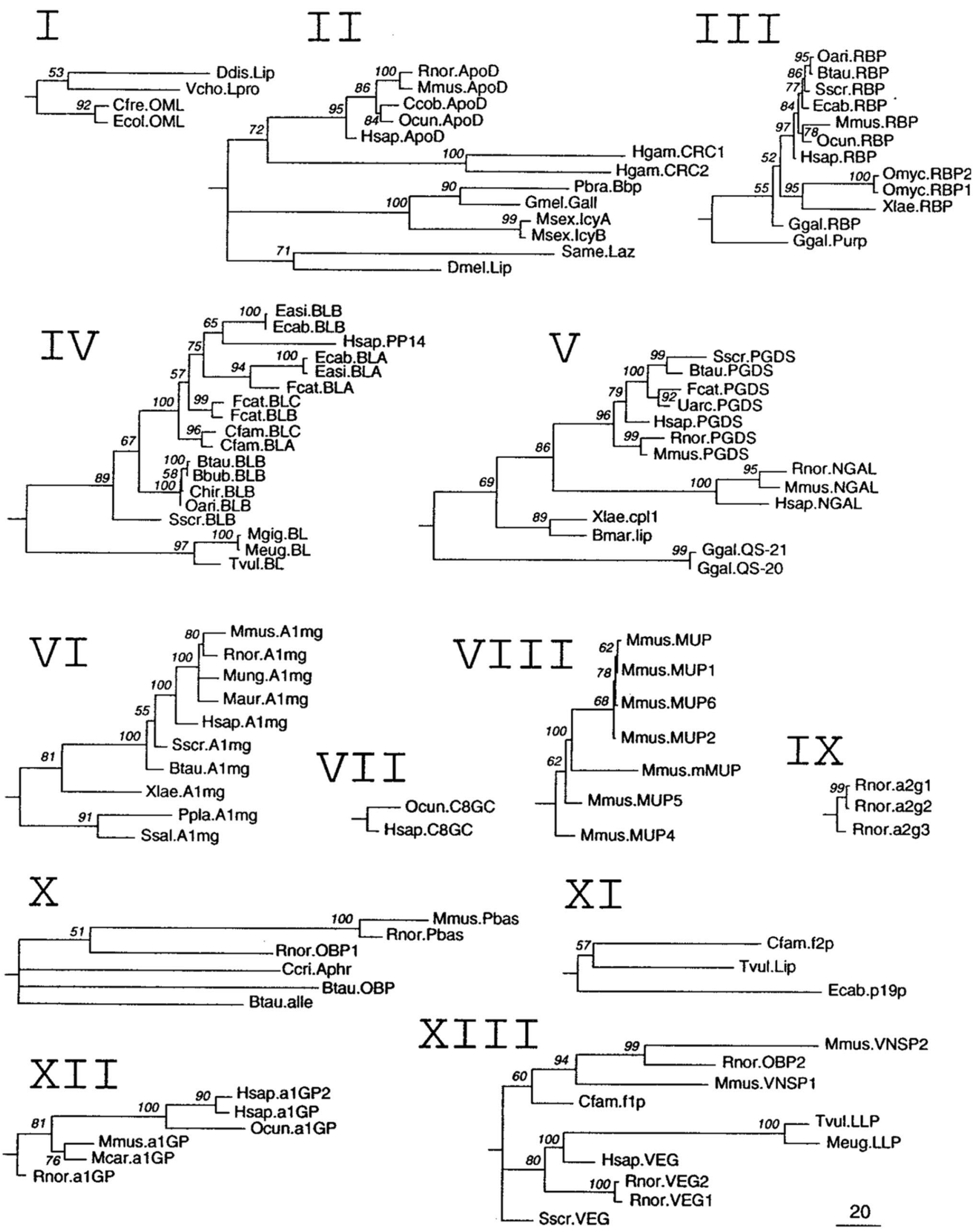

Fig. 1 Phylogenetic trees derived from maximum-likelihood analyses of the individual clades of lipocalins. Local bootstrap probability (LBP) values are indicated in each node. Polytomies reflect nodes with LBP values below 50\%. The scale bar represents branch length (number of amino acid substitutions/100 residues). Reproduced with permission from Ganfornina et al. [5] 

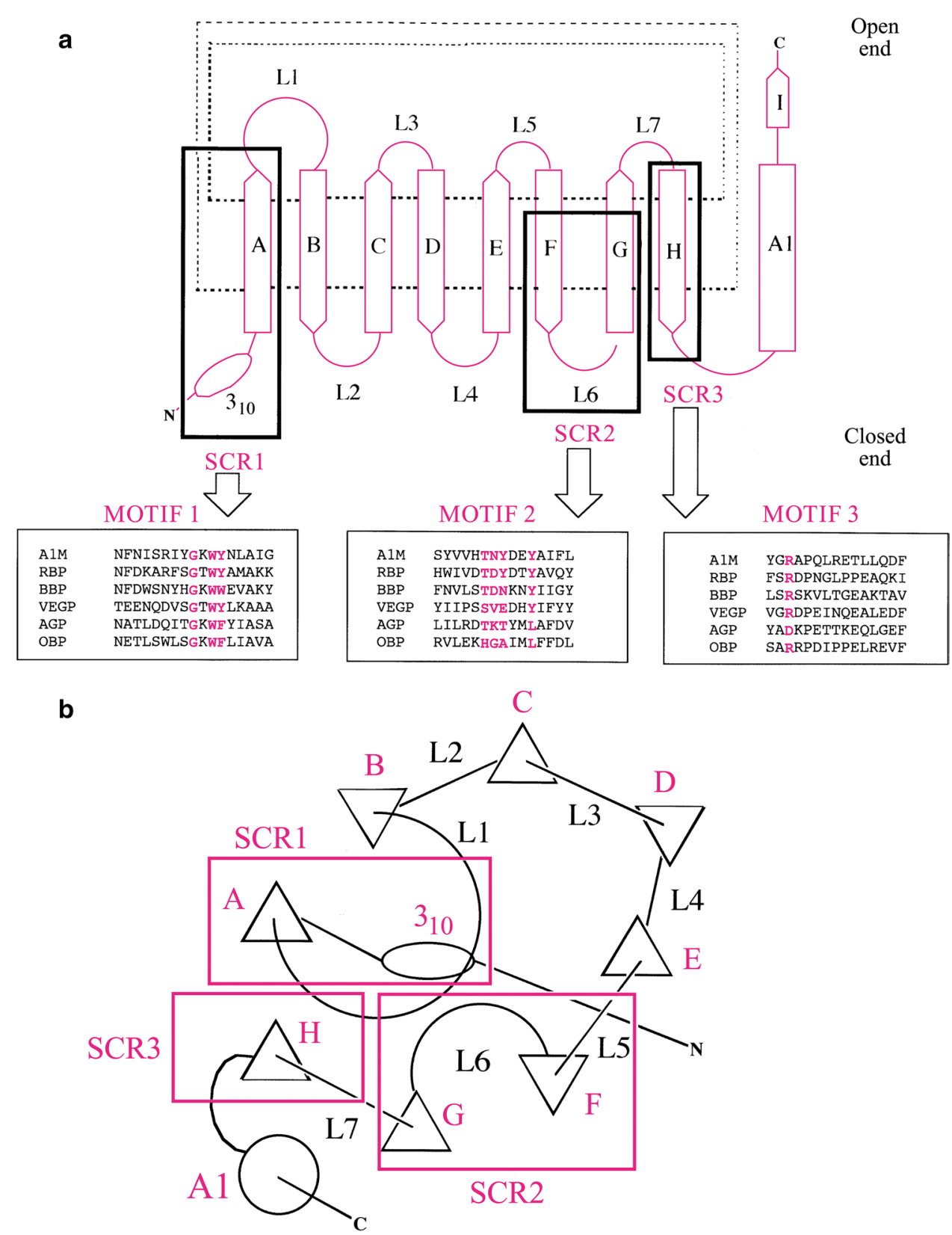

Fig. 2 Structure of the lipocalin fold. a Characteristic features of the lipocalin fold. An unwound view of the lipocalin fold orthogonal to the axis of the barrel. The nine $\beta$-strands of the antiparallel $\beta$-sheet are shown as arrows and labelled A-I. The N-terminal 310-like helix and C-terminal $\alpha$-helix (labelled A1) are also marked. The hydrogenbonded connection of two strands is indicated by a pair of dotted lines between them. Connecting loops are shown as solid lines and labelled L1-L7. The two ends of the $\beta$-barrel are topologically distinct. One end has four $\beta$-hairpins (L1, L3, L5, and L7); the opening of the internal ligand-binding site is here and so is called the open end of the molecule. The other has three $\beta$-hairpin loops (L2, L4, and L6); the N-terminal polypeptide chain crosses this end of the barrel to enter strand A via a conserved 310 helix affecting closure of this end of the barrel: the closed end of the molecule. Those parts which form the three main structurally conserved regions (SCRs) of the fold, SCR1, SCR2, and SCR3, are marked as boxes. Three sequence motifs which correspond to these SCRs are shown (MOTIF 1, MOTIF 2, and MOTIF 3). The first three sequences are from kernel lipocalins and the second three from outlier lipocalins. Note that MOTIF 1 is well conserved in all sequences, whereas the other two, particularly MOTIF 2, are only well conserved in kernel lipocalin sequences. b The lipocalin $\beta$-barrel in cross-section $\beta$-strands is shown as triangles. Triangles pointing downwards indicate a strand direction into the plane of the paper and those pointing upwards indicate a strand direction out of the plane of the paper. The view shown, down the axis of the barrel, is orthogonal to that in a. Connecting loops are shown as continuous lines. Labelling and features shown are as in $\mathbf{a}$. The closure of the sheet to form the lipocalin $\beta$-barrel breaks the symmetry of its elliptical cross-section, distinguishing between its two foci and suggesting a sidedness to the barrel also apparent in the location of the marked SCRs. Reproduced with permission from Flower et al. (1996) [2] 


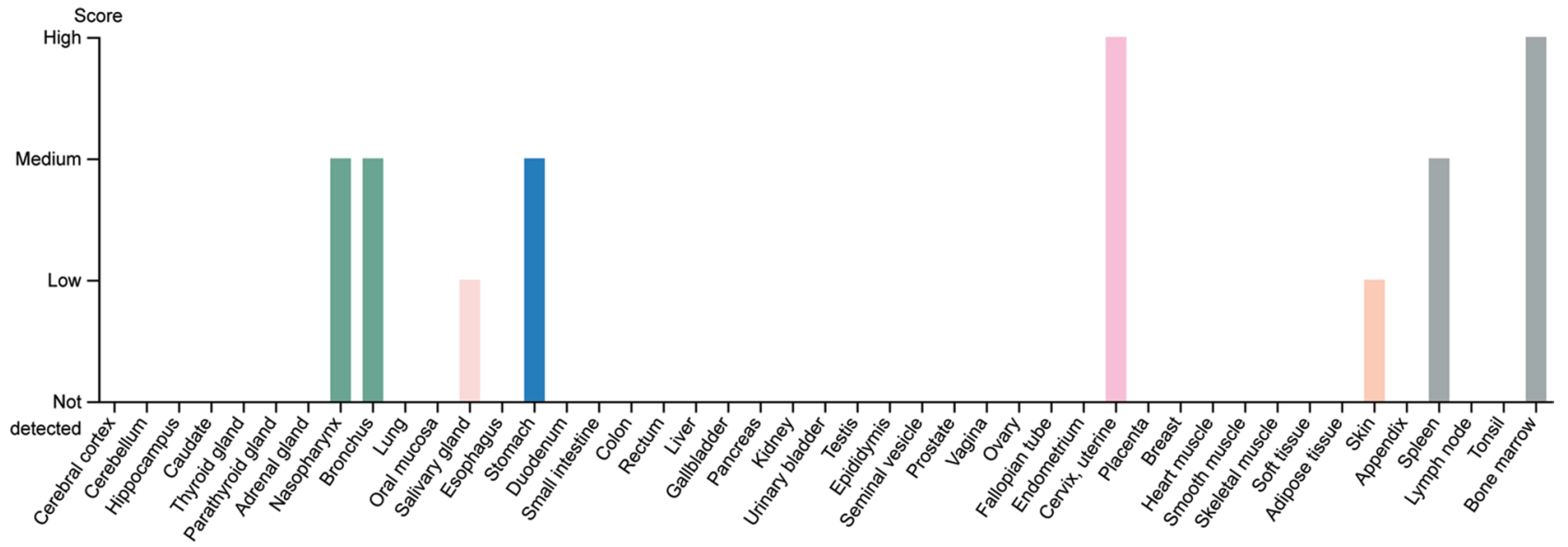

Fig. 3 LCN-2 expression in different organs in humans. The expression profile showing maximum increase in the LCN-2 protein level in bone marrow, cervix, and uterine. Reproduced from The Human

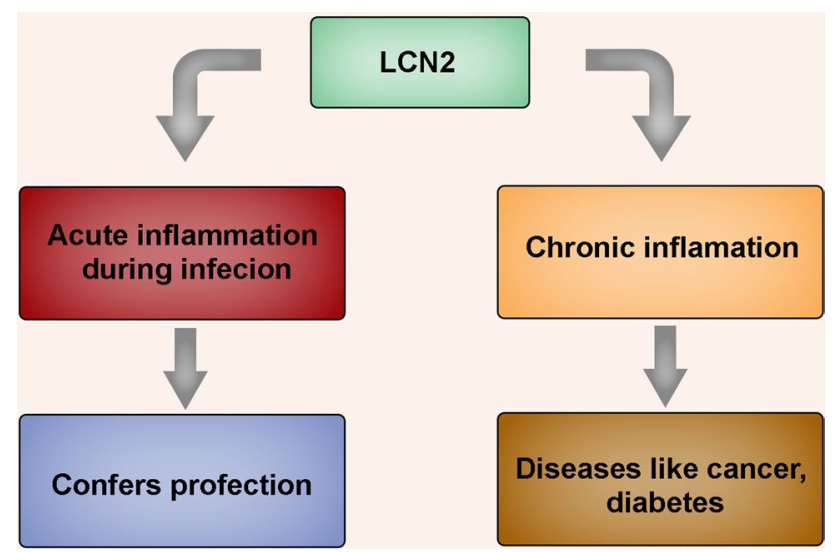

Fig. 4 Role of LCN-2 in acute and chronic inflammation. LCN-2 protects cells during bacterial and viral infections and triggers acute inflammation thereby conferring protection. However, heightened expression of the protein is also known to drive chronic inflammation, which is associated with the pathogenesis of several diseases

are different names for human LCN-2 including neutrophil gelatinase-associated lipocalin (NGAL), human neutrophil lipocalin (HNL), uterocalin, $25 \mathrm{kDa} \alpha 2$-microglobulinrelated protein, oncogene $24 \mathrm{p} 3$ protein $(24 \mathrm{p} 3)$, siderocalin, $\alpha 2 \mu$-globulin, neu-related lipocalin (NRL) in rat, and $24 \mathrm{kDa}$ superinducible protein (Sip24) in mouse [16-19]. These names were chosen based either on the observed role of LCN-2 or the specific tissue in which its expression was first noticed [16]. There are two different forms of LCN-2, one form is monomeric with a 10-min half-life and the other is dimeric with a 20-min half-life [20].

Under normal physiological conditions, the $\mathrm{LCN}-2$ mRNA is greatly expressed in bone marrow, but not in peripheral leukocytes (Fig. 3) [21]. Additionally, LCN-2
Protein Atlas Database, https://www.proteinatlas.org/ENSG000001 48346-LCN2/tissue

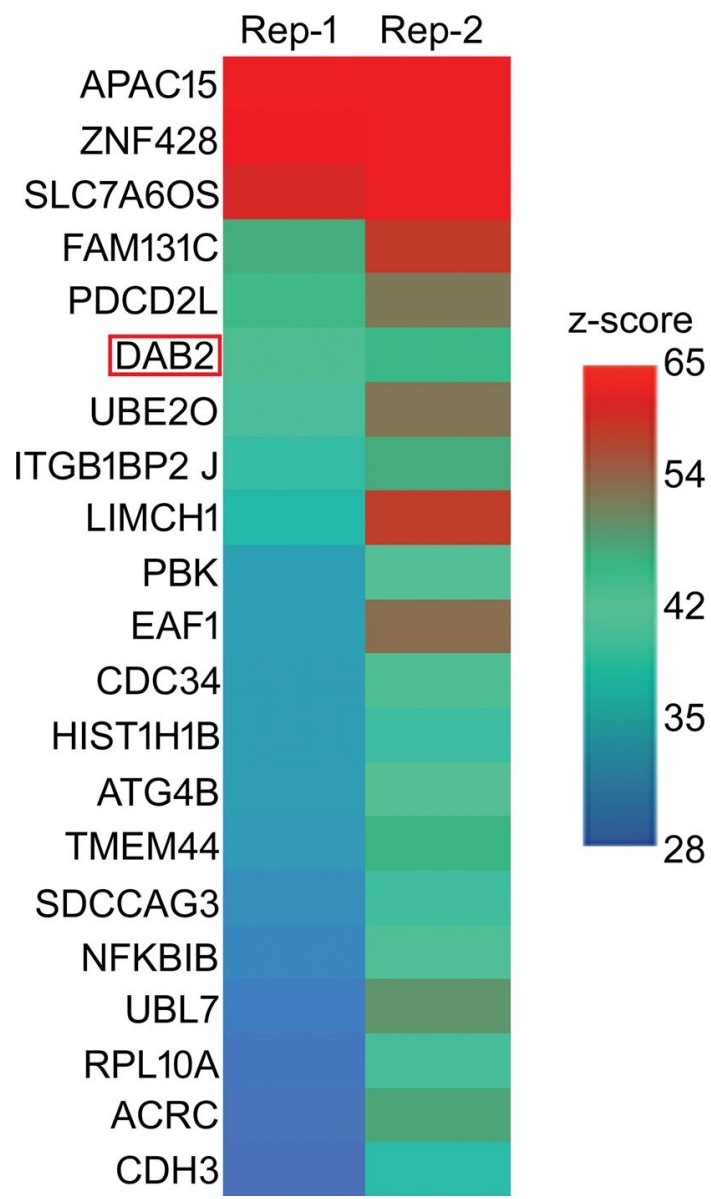

Fig. 5 DAB2 interacts with LCN-2. Human proteome array showing binding partners of $\mathrm{LCN}-2$ including DAB2 (red box) probed on HuProtTM arrays at $1 \mu \mathrm{g} / \mathrm{ml}$. Represented as $Z$-score (hit for each probe), with a cut-off of 6 and values ranging from 28 to $65 . n=3$. Reproduced with permission from Ghosh et al. [96] 


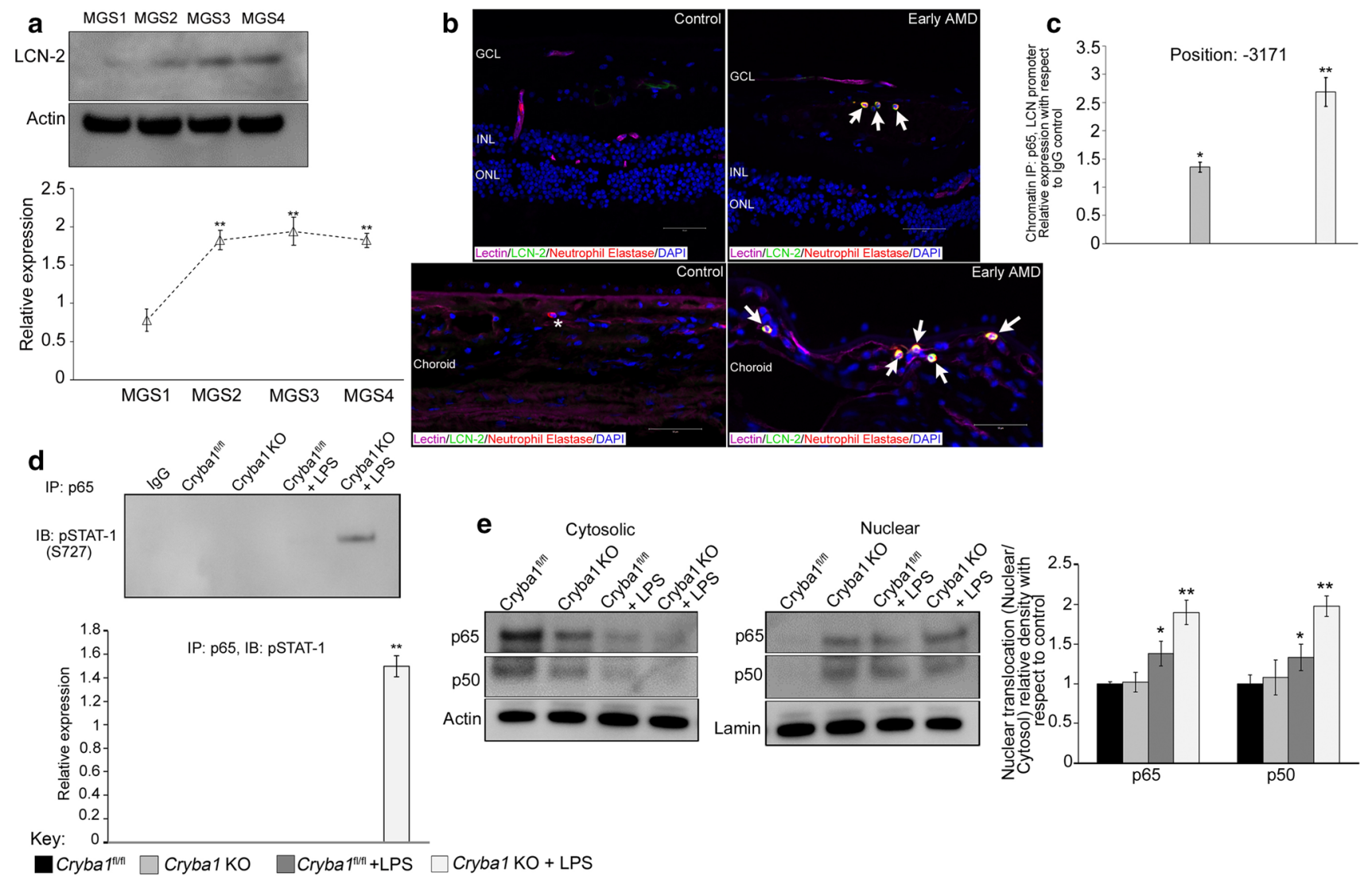

Fig. 6 Increased LCN-2 in human AMD and binding of NF- $\kappa$ B to the LCN-2 promoter. a In human samples, data from immunoblots show a significant increase in LCN-2 expression in early AMD (MGS2) compared to age-matched controls (MGS1), which persisted in the later stages of the disease ( $n=5$ control donors/and $n=3$ donors/disease stage). b Immunofluorescence demonstrates LCN-2 expressing infiltrating cells (neutrophils stained with anti-neutrophil elastase) in the sub-macular choroid and retina of an early AMD patient (arrows). In age-matched control samples, many fewer neutrophils are detected (asterisk) and they are not positive for $\mathrm{LCN}-2$. Bars $=50 \mu \mathrm{m}$. GCL ganglion cell layer, $I N L$ inner nuclear layer, $O N L$ outer nuclear layer. c ChIP analysis of LCN-2 promoter-binding activity for NF- $\mathrm{kB}$ p65 subunit in retinal cells from Crybal KO mice (+/-LPS) showing association of NF- $\mathrm{\kappa B}$ in the promoter region $(-3171)$ of the LCN-2 gene, but not in floxed controls. d Reverse ChIP analysis followed by western blotting indicated association between NF- $\mathrm{KB}$ and STAT1 in the same region as described in c. e Immunoblot shows significantly higher nuclear expression of NF-kB-p65 and p50 subunits in Crybal $\mathrm{KO}+$ LPS retinal cells, as compared to floxed control. Reproduced with permission from Ghosh et al. [92]
Fig. 7 Evidence of LCN2mediated inflammation in RPE of cKO mice. Western analysis shows significant upregulation of lipocalin-2 protein in older cKO mice compared to agematched controls. No significant change was found in younger animals. Adapted with permission from Valapala et al. [91]
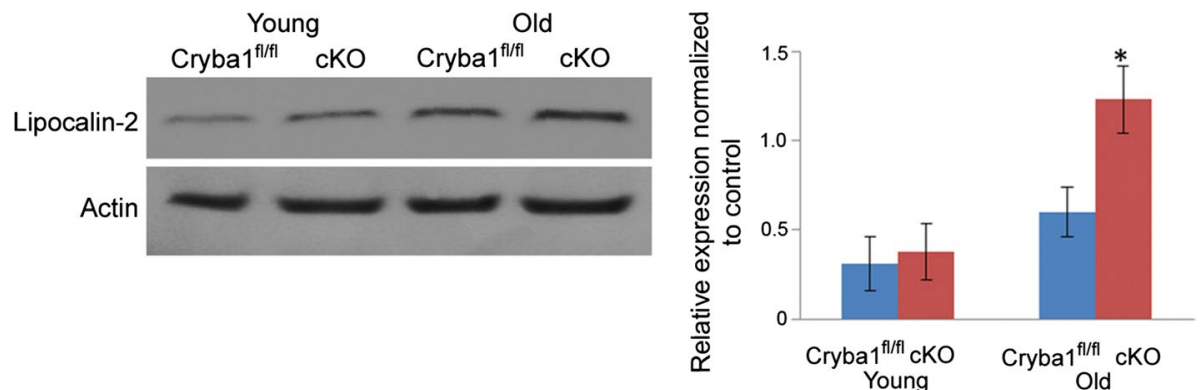

expression is induced during neutrophil development [12]. Higher levels of LCN-2 are found in tissues that are constantly exposed to microorganisms including prostate, salivary gland, uterus, stomach, colon, and appendix. Moreover, in some tissues such as kidney and liver, the level of LCN-2 is reduced during senescence $[16,22]$. Although LCN-2 expression begins in the embryo [23], it has been demonstrated that it is strongly activated in inflamed organs, where it is expressed either by different resident cells or by circulating immune cells which enter the tissue [16, 24, 25]. A low level of LCN-2 is detectable in bodily fluids, however, under pathological conditions, this level may increase [16, 26]. 
Fig. 8 Heatmap of Z-scores of 78 protein hits identified for all triplicates (Rep1/2/3) from 14,693 human proteins on the microarray. The hits were sorted by their mean value of $Z$-scores. Reproduced with permission from Shang et al. 2017 [95]

In general, lipocalins bind to specific cell-surface receptors to transport ligands inside cells through receptor-mediated endocytosis [27]. Two different cell-surface receptors for LCN-2 have been described: solute carrier family 22 member 17 (SLC22A17, 24p3R or NGALR2) and lowdensity lipoprotein-related protein 2 (LPRP2 or megalin) [27-29]. High levels of 24p3R are regularly present in specific cells, including macrophages, neutrophils [30, 31], epithelia of respiratory and alimentary tracts [32], kidney epithelial cells [27], astrocytes [33], microglia [34], and neurons [35]. Megalin, a multi-ligand endocytic receptor, is highly expressed in some types of absorptive epithelial cells such as thyroid cells, epididymal, renal proximal tubule [36-42], and neuro-epithelium [43]. Sensory organs including eye (specifically the retinal ganglion cells) and ear also express megalin [44-49]. Additionally, it has been shown that in the optic nerve, megalin is selectively expressed by astrocytes during the development of oligodendrocyte precursor cells [50].

\section{$\mathrm{LCN}-2$ function in health and diseases}

LCN-2 was first identified as a neutrophil granule component, with a strong binding affinity to bacterial catecholatetype ferric siderophores [51]. Iron is essential for bacterial growth and perpetuation, and lipocalin- 2 confers its bactericidal affect against a number of bacterial species by chelating siderophore-bound iron and making it unavailable for bacterial utilization [51-53]. It has been linked as a definitive marker for several bacterial acute infections in humans [54]. LCN-2 is known to be highly elevated in patients with urinary tract [55, 56], Helicobacter pylori [57] and particularly Klebsiella pneumoniae infections [58], and it is thought to be a very useful marker to assess the severity and potential mortality of patients with community-acquired pneumonia [59]. The expression of the $l c n 2$ gene has also been found to be upregulated in peripheral blood mononuclear cells (PBMCs) from severe acute respiratory syndrome (SARS) patients [60]. It is now known that human immunodeficiency virus (HIV) infection is associated with adipose tissue inflammation and LCN-2 activation [61]. Reduced $\mathrm{LCN}-2$ levels are seen in nasopharyngeal aspirate samples from patients with severe influenza A(H1N1)pdm09 virus infection [62]. These results indicate that LCN-2 serves as an important marker for several infectious diseases, including HIV-related adipose tissue dysfunction and severe H1N1 infection [61, 62].

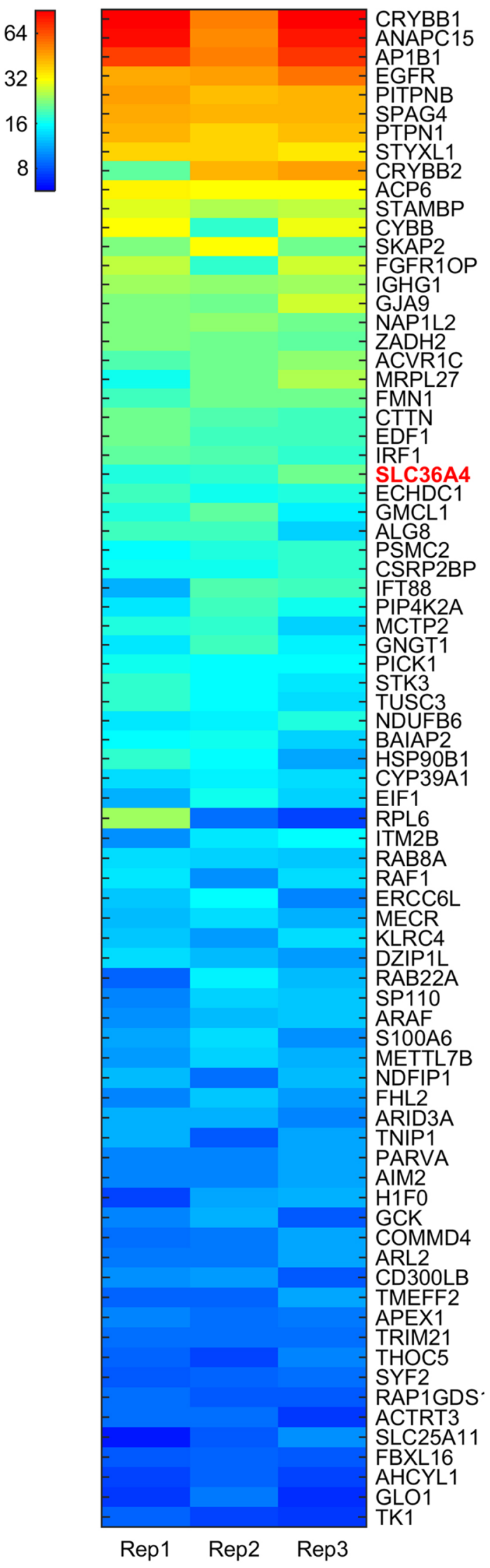

Rep1 Rep2 Rep3 


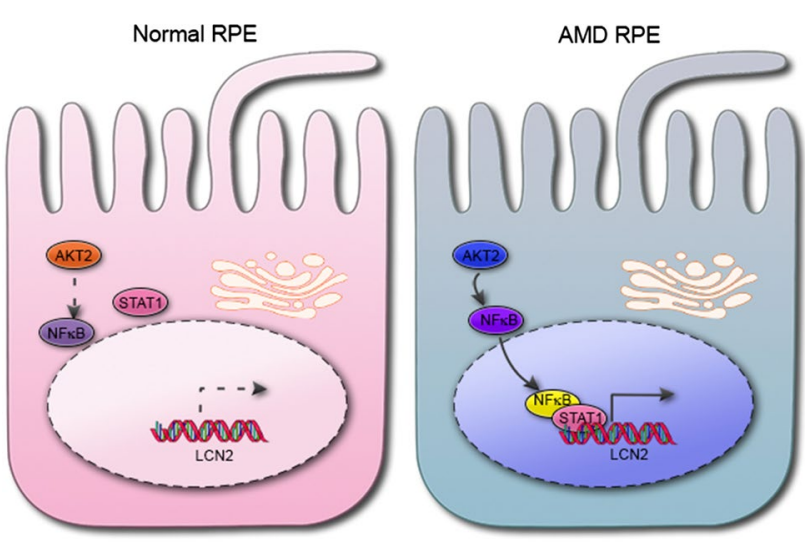

Fig. 9 AKT2-NF-кB-LCN-2 signaling in AMD. In AMD, AKT2dependent NF- $\mathrm{KB}$ and STAT1 nuclear translocation drives lcn2 gene expression in the retinal pigment epithelium (RPE) cells (right panel), which is not observed in the control RPE cells (left panel). These upstream regulators of $\mathrm{LCN}-2$ could be used as potential targets for lowering LCN-2 mRNA expression in AMD

LCN-2 also plays an important role in immune activation during acute infection [53]. It is known to be expressed in macrophages and polymorphonuclear cells (PMNs) and to confer protection in an animal model of nephrotoxic serum nephritis induced by either acute kidney injury or bacterial infection by triggering apoptosis in the renal epithelial cells and limiting cytokine production by the TLR2 pathway [30]. In animal models of Salmonella typhimurium infection, LCN-2 confers host defense by regulating iron homeostasis and the inflammatory pathway in macrophages [63, 64]. In vivo models for mucosal infection due to Escherichia coli and Klebsiella pneumoniae exposure show increased expression of LCN-2 in an IL-22-dependent manner in intestinal epithelial cells, as part of the protective host-defense mechanism against such infection at mucosal surfaces [65]. In addition to the protective role of $\mathrm{LCN}-2$ during acute infection, there is contrasting evidence which suggests otherwise. It has been shown that LCN-2 worsens pneumococcal pneumonia infection outcomes by deactivating alveolar macrophages in an animal model [66]. LCN-2 works as a source of iron to Mycobacterium tuberculosis in infected macrophages, facilitating mycobacterial growth in vivo [67]. LCN-2 also regulates iron homeostasis and exacerbates endotoxin-mediated sepsis [68], and regulates activation and tissue homing of innate immune cells, like neutrophils, during bacterial infection $[69,70]$. LCN-2 also aggravates acute infectious colitis in mice by modulating PPAR $\gamma$ in intestinal epithelial cells [71].

Moreover, LCN-2 is known to be upregulated in several chronic diseases. Increased LCN-2 expression is seen in a variety of pathological states in the central nervous system, such as gliomas [72, 73], autoimmune disorders [74], brain injury $[75,76]$, and neurodegeneration $[34,77,78]$.
Elevated expression of the protein was observed in mouse models of systemic lupus erythematosus, collagen-induced arthritis, and serum-transfer arthritis [79] and it has also been shown that deficiency of LCN-2 ameliorates experimental autoimmune encephalomyelitis in mice [80]. LCN-2 upregulation is linked to several human cancers with poor prognoses [81-83]. The elevated expression of the protein is also associated with obesity, insulin resistance, and hyperglycemia [84, 85], and with Crohn's [86], chronic kidney [87], and liver [88] diseases. It has been also shown that the level of LCN-2 is significantly increased in the plasma and cerebrospinal fluids of patients with multiple sclerosis relative to healthy individuals, suggesting that $\mathrm{LCN}-2$ may be an applicable biomarker for the disease [74].

These results indicate that $\mathrm{LCN}-2$ plays a critical role in differential regulation of inflammation during acute infections and in the progression of several chronic diseases, thereby providing impetus for targeting this important adipokine for therapeutic interventions (Fig. 4). Moreover, our recent findings from a high-throughput protein-protein interaction array revealed that $\mathrm{LCN}-2$ binds to several proteins responsible for regulating cell adhesion/migration, autophagy, inflammation, and post-translational modifications (Fig. 5). These findings suggest a multi-faceted role of this protein in regulating a number of cellular functions during normal and disease states.

\section{Role of LCN-2 in ocular diseases: focus on age-related macular degeneration (AMD)}

Consistent with its role in inflammation, apoptosis, and stress resistance during acute infections and in chronic diseases (as reviewed in section "LCN-2 function in health and diseases"), LCN-2 has recently been shown to be upregulated in a number of ocular pathologies. A few groups have reported that expression of $\mathrm{LCN}-2$ was increased with the progression of experimental retinal degeneration induced in animal models by various factors and, most importantly, in the retinae of human AMD donors (Fig. 6) and in a mouse model (Fig. 7) with AMD-like pathology [89-92]. One of the easiest ways to induce retinal degeneration is to expose dark-adapted animals to high-intensity fluorescent light right after chemical pupil dilation $[89,93]$. Both the LCN-2 mRNA and protein levels were significantly increased in the whole retinae of the rats after such induction of retinal degeneration, compared to the controls. Moreover, this increase coincided with the increased expression of Bim and caspase-3-markers of apoptosis. Importantly, knockdown or overexpression of LCN-2 in the retina (by intravitreal injections of either LV-shLCN-2 or LV-LCN-2) resulted in the corresponding changes in the expression of apoptotic markers, suggesting that LCN-2 is an upstream regulator of 


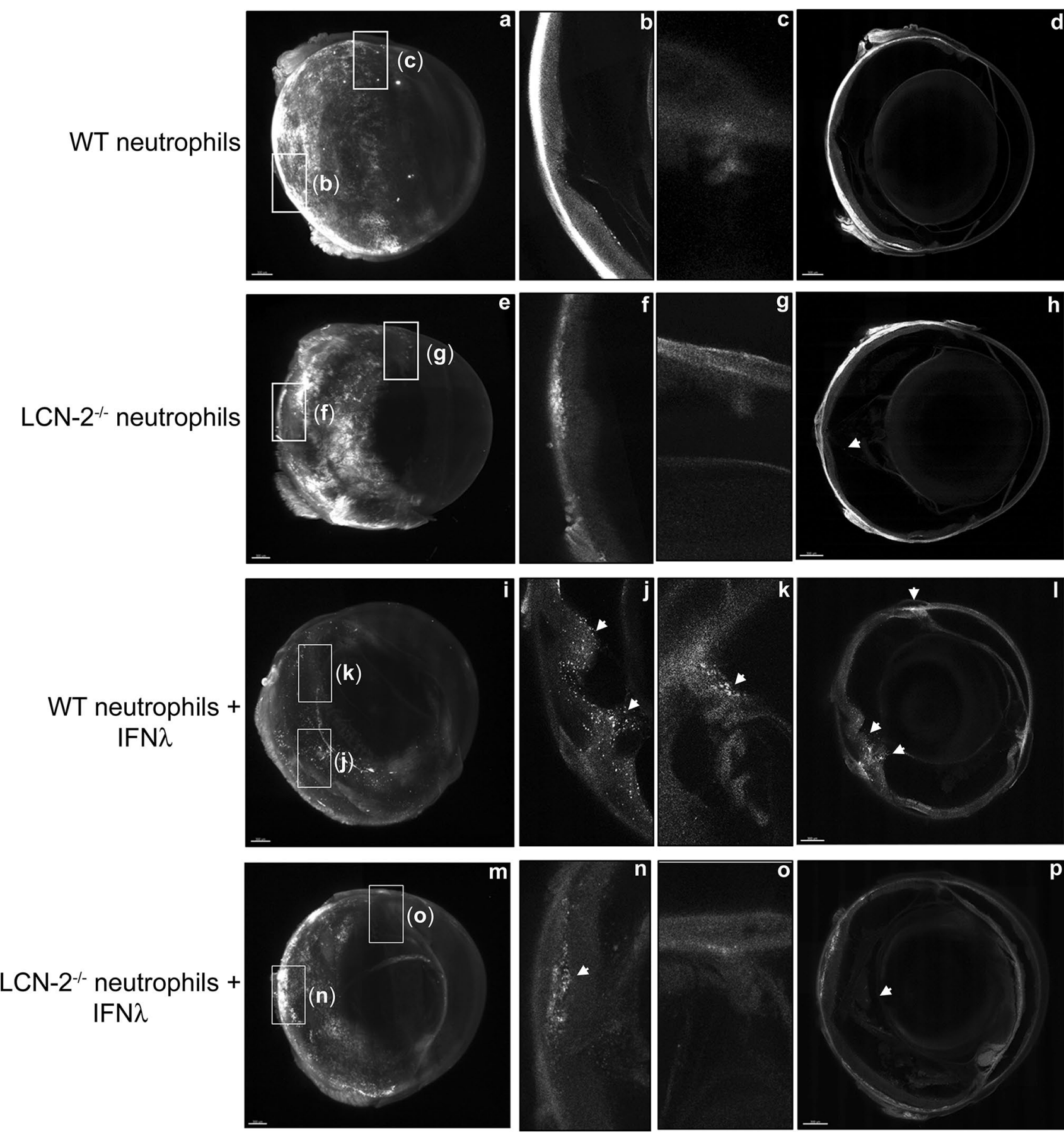

Fig. 10 IFN $\lambda$ triggers neutrophil homing into the eye in vivo. Ribbon scanning confocal microscopy (RSCM) was used to image neutrophil infiltration into whole cleared eyes from NOD-SCID mice intravenously injected with; untreated WT and $\mathrm{LCN}-2^{-1-}$ neutrophils or IFN $\lambda$-exposed $(200 \mathrm{U} / \mathrm{ml}), \mathrm{WT}$ or $\mathrm{LCN}-2^{-/-}$neutrophils, tagged with red CMTPX. a 3D volumetric and $\mathbf{d}$ orthogonal projections from whole eyes obtained from mice injected with, WT neutrophils, did not show neutrophil homing $\mathbf{b}$ into the retina or $\mathbf{c}$ in through the aqueous humor drainage route (Schlemm's canal, a channel at the limbus and forms the joining point between the cornea and sclera, encircling the cornea). Mice injected with $\mathrm{LCN}-2^{-/-}$neutrophils showed $\mathbf{h}$ prevalence of neutrophils in the eye (arrow), but no infiltration was noticed into the e, f retina or e, $\mathbf{g}$ Schlemm's canal. Mice injected with IFN $\lambda$-treated WT neutrophils showed noticeable infiltration of neutrophils into the $\mathbf{i}, \mathbf{l}$ eye (arrows), particularly in the $\mathbf{j}$ retina (arrow) and $\mathbf{k}$ Schlemm's canal (arrow), relative to untreated WT neutrophils. NOD-SCID mice injected with IFN $\lambda$-exposed LCN$2^{-/-}$neutrophils showed relatively lower numbers of neutrophils in the eye (arrow) (m, p), with respect to IFN $\lambda$-treated WT neutrophils, especially in the $\mathbf{n}$ retina (arrow). There was no visible neutrophil infiltration into o Schlemm's canal. $n=1$. Scale bar, $300 \mu \mathrm{m}$. Reproduced with permission from Ghosh et al. [96] 

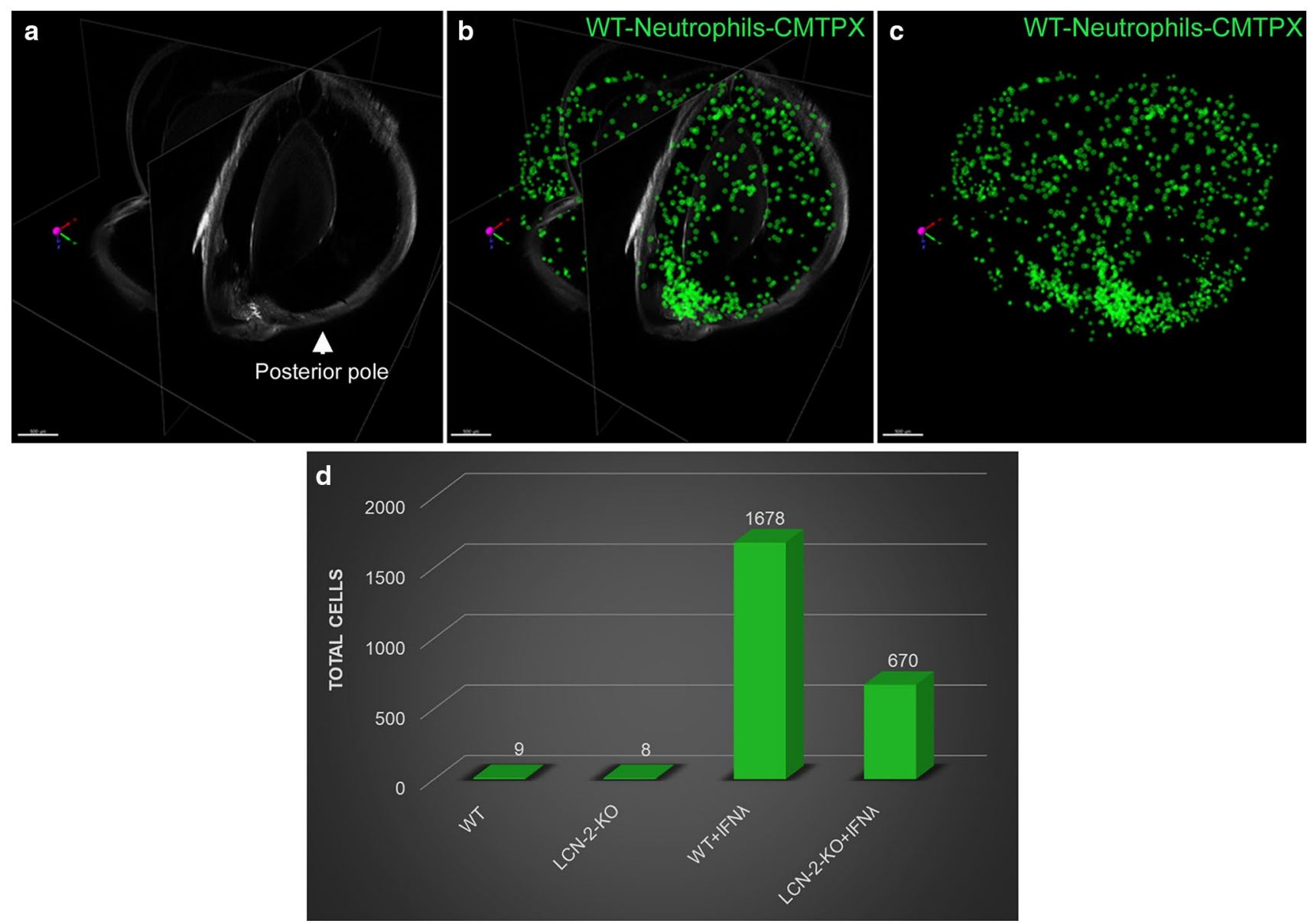

Fig. 11 LCN-2 is responsible for neutrophil sequestration into the eye. a Orthogonal projections from all three dimensions of a whole eye from a mouse injected with WT neutrophils + IFN $\lambda$. Cells within the retina and Schlemm's canal were extracted as spot counts in Imaris software. Cells are depicted as green spheres $\mathbf{b}$ with and $\mathbf{c}$ without the orthogonal projection. d Counts extracted from all groups dem-

apoptosis in the light-induced model of retinal degeneration [93].

Another group used ATP-binding cassette subfamily A member $4(\text { Abca } 4)^{-1-}$ retinol dehydrogenase 8 $(R d h 8)^{-/-}$double-knockout mice to study retinal degeneration caused by the disruption of the visual cycle [94]. These mice exhibit several features of Stargardt disease (a form of hereditary macular degeneration that affects youths) as well as AMD. Exposure of $A b c a 4^{-1-} R d h 8^{-1-}$ mice (an animal model for Stargardt disease and AMD) to high-intensity light exacerbated retinal damage allowing for studying the role of the acute stress response in retinal degeneration. Strikingly, LCN-2 mRNA expression was 22-fold higher in the eyes of $A b c a 4^{-/-} R d h 8^{-/-}$mice that were exposed to highintensity light compared to those kept under normal lighting conditions. The retinal pigment epithelium (RPE) and the retina were identified to be the source of the elevated onstrated an increase in neutrophil number (cell count) in the NODSCID mice injected (intravenous) with IFN $\lambda$-treated WT neutrophils compared to untreated controls, whereas loss of LCN-2 in neutrophils $\left(\mathrm{LCN}-2^{-/-}\right)$showed reduced infiltration even after IFN $\lambda$ exposure. $n=1$. Scale bar, $500 \mu \mathrm{m}$. Reproduced with permission from Ghosh et al. [96]

LCN-2 [89]. Importantly, the expression of the LCN-2 receptor $24 \mathrm{p} 3 \mathrm{r}$ was increased in the RPE after exposure of $A b c a 4^{-/-} R d h 8^{-/-}$mice to intense light, suggesting the possible involvement of a receptor-mediated effect during the development of retina degeneration [94]. To examine the exact role of $\mathrm{LCN}-2$ in retinal degeneration, $L C N$ $2^{-1-} A b c a 4^{-1-} R d h 8^{-/-}$triple-KO mice were generated in a follow-up study [94]. As expected, the light-induced retinal damage was exaggerated by the introduction of the third

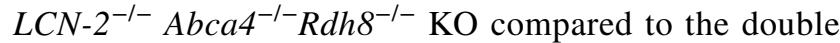
$A b c a 4^{-1-} R d h 8^{-1-} \mathrm{KO}$, with significant upregulated expression of pro-inflammatory genes and activation of microglia [94]. The in vivo studies were complemented by in vitro data using hiPS-RPE cells that demonstrated the antiapoptotic and indirect antioxidant (through overexpression of heme oxygenase 1 and superoxide dismutase 2) effects of LCN2. Taken together, it can be concluded that $\mathrm{LCN}-2$ plays a 

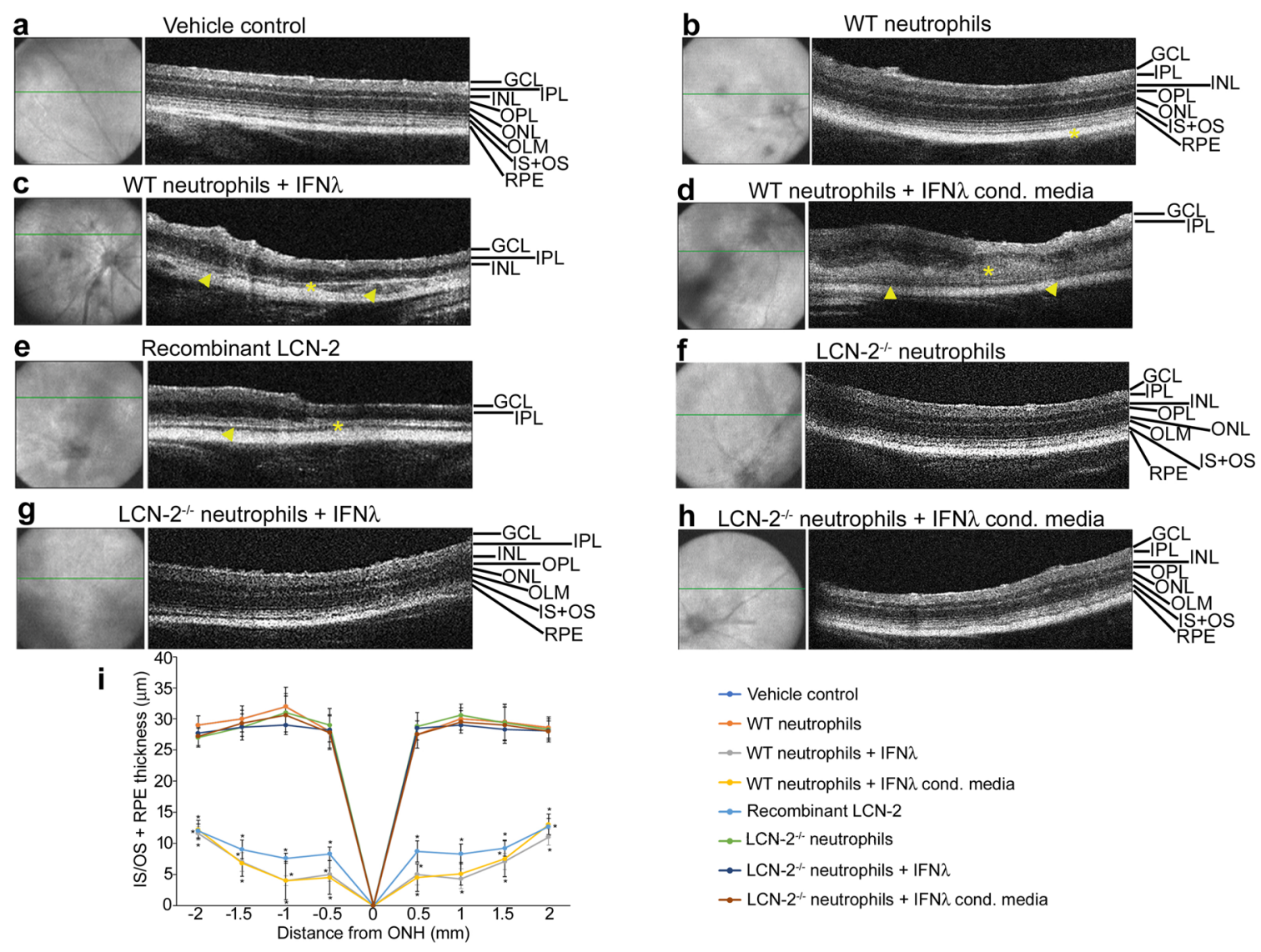
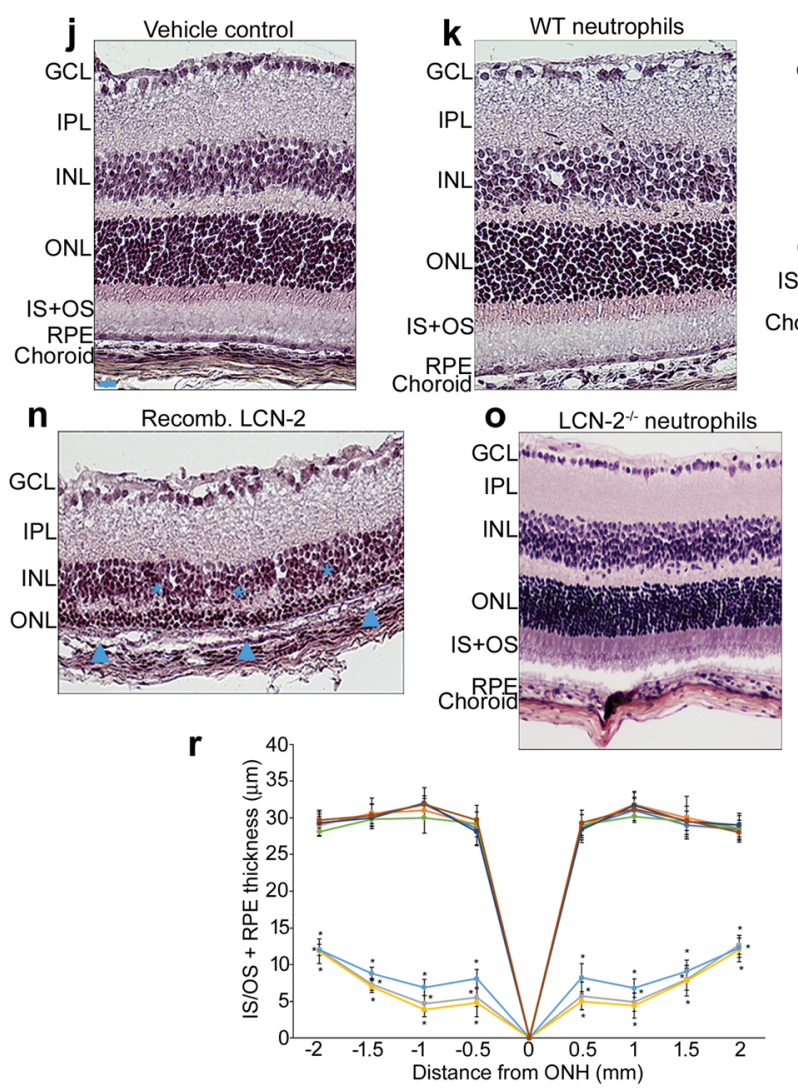

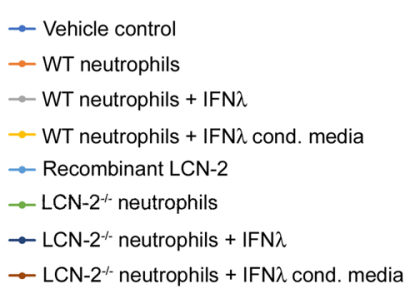

$\rightarrow$ LCN-2-/ neutrophils + IFN $\lambda$ cond. media
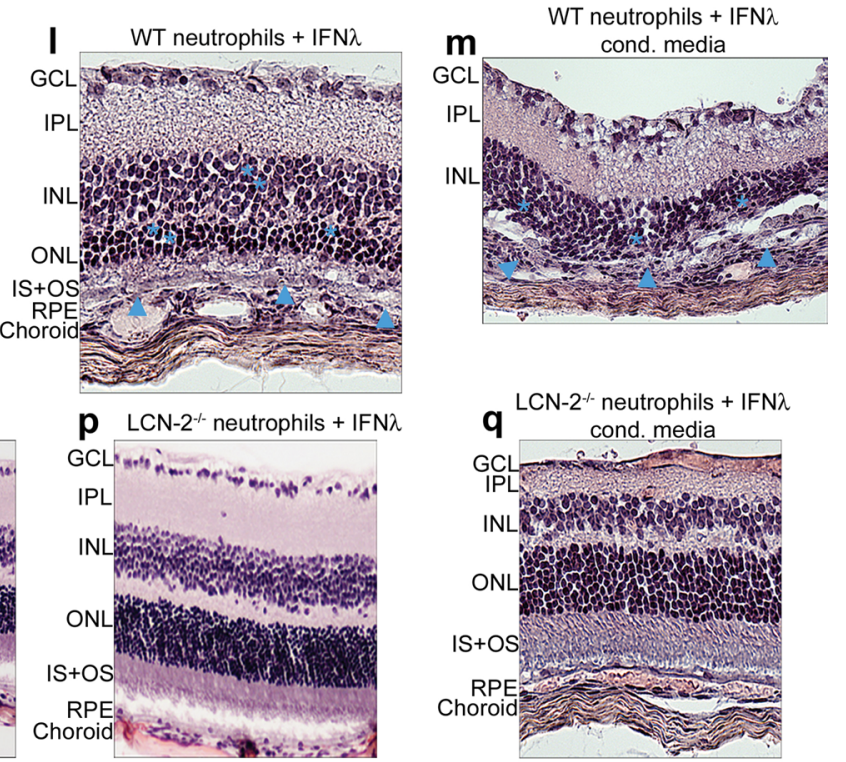

- Vehicle control

$\rightarrow$ WT neutrophils

$\rightarrow$ WT neutrophils + IFN $\lambda$

$\rightarrow$ WT neutrophils + IFN $\lambda$ cond. media

$\rightarrow$ Recombinant LCN-2

$\rightarrow$ LCN-2-- neutrophils

$\rightarrow$ LCN-2-r neutrophils + IFN $\lambda$

$\rightarrow$ LCN-2-r neutrophils + IFN $\lambda$ cond. media 
4Fig. 12 LCN-2 laden neutrophils promote AMD-like pathology. Representative spectral-OCT images of retinas from NOD-SCID mice injected sub-retinally with a vehicle (HBSS) or b WT neutrophils revealed normal retinal structure. In contrast, mice injected with; WT neutrophils pre-treated with either c recombinant IFN $\lambda$ (200 U/ $\mathrm{ml}$ ), d conditioned media from IFN $\lambda$ overexpressing mouse RPE cells (1:1 diluted), or e recombinant LCN-2 (10 pg/ml), show apparent changes in the ONL and INL layers (asterisks), concomitant with severe loss of RPE and IS + OS layer (yellow arrow heads). These alterations were not observed in mice injected with; $\mathbf{f}$ untreated neutrophils from $\mathrm{LCN}-2^{-/-}$mice or $\mathbf{g}$, $\mathbf{h}$ IFN $\lambda$-exposed $\mathrm{LCN}-2^{-/-}$neutrophils. i Representative spider plot showing the thickness of the IS/OS + RPE layers using the OCT images among the experimental groups. $n=10$. ${ }^{*} P<0.05$ (one-way ANOVA and Tukey's post hoc test). Hematoxylin-eosin staining showed no noticeable alterations in; $\mathbf{j}$ vehicle treated or mice injected with untreated $\mathbf{k}$ WT or l-q LCN-2 $2^{-/-}$neutrophils ( \pm ) IFN $\lambda$. However, significant alterations were observed in the INL or ONL (blue asterisks) and RPE/IS + OS (blue arrow heads), in NOD-SCID mice sub-retinally injected with; $\mathbf{l}, \mathbf{m}$ IFN $\lambda$-exposed WT neutrophils or $\mathbf{n}$ recombinant LCN-2. $\mathbf{r}$ Representative spider plot from all of the experimental groups showing the thickness of the IS/OS + RPE layers using the H\&E images. $n=5$. $* P<0.05$ (one-way ANOVA and Tukey's post hoc test), Scale Bar, $20 \mu \mathrm{m}$. Reproduced with permission from Ghosh et al. [96]

protective role in retinal degeneration caused by the disruption of the visual cycle [94].

Our lab has also reported increased levels of LCN-2 during the progression of AMD and focused on the upstream regulation of LCN-2 using the Crybal KO mouse model that exhibits a strong AMD-like phenotype caused by defective lysosomal clearance in the RPE cells (Fig. 6) [91, 92]. We have provided novel evidence that during chronic inflammation and the onset of the disease state, expression of $\mathrm{LCN}-2$ in the retina is regulated not only by NF- $\mathrm{BB}$, but also by STAT1, and that they may act together as an indispensable promoter-binding complex for stimulating $l c n$-2 gene expression in LPS-treated Crybal KO mice (Fig. 6) [92]. Furthermore, a human proteome high-throughput microarray assay revealed a novel interaction between $\beta$ A3/A1-crystallin (protein encoded by Crybal) and AKT2 (Fig. 8) [95], which, in turn, is associated with $\beta \mathrm{B} 2$-crystallin when phosphorylated. $\beta \mathrm{B} 2$ crystallin is also the strongest binding partner for $\beta$ A3/A1-crystallin (Fig. 8), and this association may regulate phosphorylation of AKT2 in the inflamed retina [92]. Finally, AKT2 regulates phosphorylation of IKK $\alpha$, which is required for activation of NF- $\mathrm{KB}$, which, in turn, regulates expression of $\mathrm{LCN}-2$ in the retina both in the mouse model and in AMD patients [92]. Overall, our study revealed a novel AKT2-NF-KB-LCN-2 signaling axis that may be a potential therapeutic target for AMD (Fig. 9) [92]. We have also shown that LCN-2 positive neutrophils infiltrate the retina of AMD patients, but not in the retinas of control subjects (Fig. 6) [92], indicating a possible role of these cells in AMD pathogenesis. Our recent publication also suggests that $\mathrm{LCN}-2$ upregulation in neutrophils during inflammation drives its activation and tissue homing (Figs. 10, 11; Movie 1), thereby potentiating degenerative changes in the retina (Fig. 12), similar to changes observed in atrophic or dry AMD [96]. Interestingly, loss of LCN-2 in these neutrophils (neutrophils obtained from
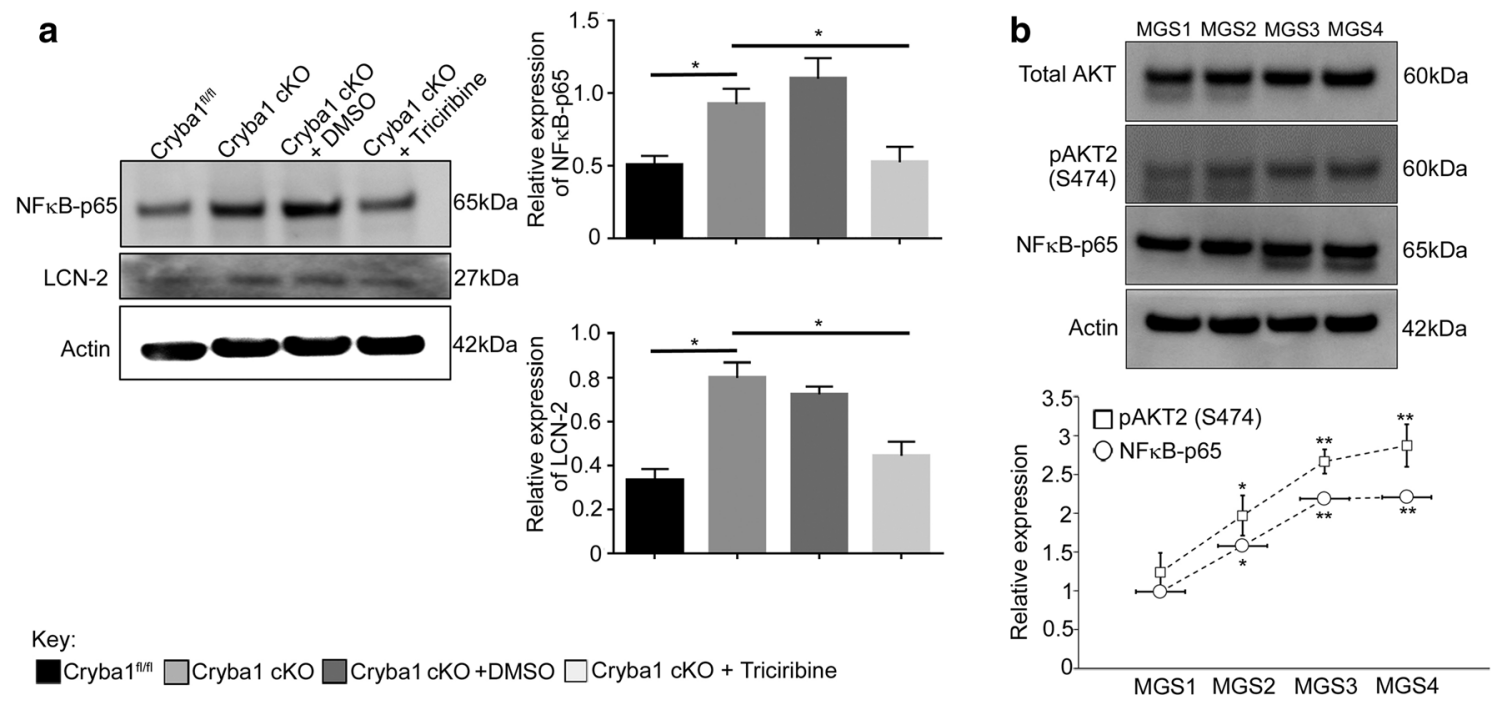

Fig. 13 Activation of $\mathrm{LCN}-2$ through the AKT2/NF- $\kappa \mathrm{B}$ axis. a Immunoblot and summary of densitometry showing increased expression of both NF- $\mathrm{kB}-\mathrm{p} 65$ subunit and $\mathrm{LCN}-2$ in the retinas from 1 year old Crybal cKO mice. After intravitreal injections of Triciribine in Crybal cKO mice, the activation of both NF- $\mathrm{KB}$ and $\mathrm{LCN}-2$ was significantly reduced. b Immunoblot data showing significant increase in expression of pAKT2 (S474) and NF-kB-p65 subunit in retinas of early AMD subjects compared to age-matched controls, which increased with disease severity ( $n=3$ donors/stage). Error bars indicate s.d.; $* P<0.05$. $* * P<0.01$ relative to $C r y b a l^{\mathrm{f} / \mathrm{fl}}$. Adapted with permission from Ghosh et al. [92] 
LCN-2 knockout mice) did not trigger retinal infiltration or degenerative changes even in the presence of inflammatory stimuli (Figs. 10-12). Taken together, these results indicate that LCN-2 is important for regulating neutrophils activation, retinal infiltration, and concomitant degenerative changes in the retina during AMD pathogenesis [96].

Recently, Parmar et al. suggested the existence of a negative feedback loop between LCN-2 and NF- $\mathrm{BB}$, based on the finding that pre-treatment of hiPS-RPE with LCN-2 led to a decrease in the nuclear translocation of NF- $\mathrm{KB}$ p65 (a well-characterized hallmark of NF- $\mathrm{BB}$ activation) [94]. In agreement with Parmar's in vitro data, LCN-2-mediated regulation of NF- $\mathrm{KB}$ activation has also been documented in inflammation during progression of endotoxin-induced uveitis, a well-established model of acute ocular inflammation. LCN-2 was significantly upregulated in the retinae of the rats after induction of uveitis, and played a protective antiinflammatory role by negative regulation of phosphorylation and nuclear translocation of NF- $\mathrm{KB}$ p65 in Muller cells and retinal tissues [90]. An earlier study conducted using eyes from horses suffering from autoimmune equine recurrent uveitis also reported upregulation of LCN-2 expression compared to healthy eyes. However, in contrast to endotoxininduced uveitis, where LCN-2 was mostly localized to the outer nuclear layer of the retina, in autoimmune uveitis, LCN-2 was present throughout the whole retina [89, 97]. Interestingly, infiltrating cells were found to express both LCN-2 and matrix metalloproteinase 9 (MMP-9), indicating the possibility of MMP-9 stabilization by LCN-2 [97]. Notably, LCN-2 was also found to be overexpressed and co-localized with MMP-9 in another ocular pathology, pterygiuma wing-shaped, epithelial-covered fibrovascular growth on the cornea, frequently characterized by inflammation and neovascularization [98]. Possible stabilization of MMP-9 by
Fig. 15 Inhibiting AKT2 phosphorylation blocks neutrophil infiltration into the retina and rescues early RPE changes in Crybal cKO mice. a Flow cytometry dot plots denoting monocytes, macrophages, and neutrophils from mouse retina (as explained in Fig. 1a) [96]. The neutrophil population $\left(\% \mathrm{CD} 45^{\text {high }} \mathrm{CD} 11 \mathrm{~b}^{+} \mathrm{Ly} 6 \mathrm{C}^{\text {high }} \mathrm{Ly} 6 \mathrm{G}^{+}\right.$ cells, red gated) significantly increased in the 12 month Crybal cKO mouse retina \pm intravitreal vehicle treatment, compared to agematched $\mathrm{Crybal} 1^{\mathrm{fl} / \mathrm{fl}}$ (control). Intravitreal treatment with the AKT2 inhibitor (CCT128930) significantly reduced neutrophils in cKO retina. Graphs denote \% $\mathrm{CD} 45^{\text {high }} \mathrm{CD} 11 \mathrm{~b}^{+}$Ly $6 \mathrm{C}^{\text {high }} \mathrm{Ly} 6 \mathrm{G}^{+}$cells. $n=4$. $* * P<0.01$ and ${ }^{\#} P<0.05$ (one-way ANOVA and post hoc test). b-d Representative histological sections (H\&E) of retina from 1 year old $C r y b a 1^{\mathrm{f} / / \mathrm{ll}}$ mouse, showing normal structure (b). Agematched Crybal cKO mouse (c) intravitreally injected with vehicle (2.5\% DMSO in PBS) shows RPE and photoreceptor lesions with pigmentation changes (arrows). Inset in $\mathbf{c}$ shows higher magnification of RPE lesions indicating possible debris accumulation between Bruch's membrane and RPE and separation of photoreceptors from RPE (arrows). In contrast, inhibitor (CCT128930, inhibits AKT2 activation) treated Crybal cKO mice (d), exhibited normal structure after 4 weeks. e Bar graph showing decrease in number of sub-retinal drusen-like deposits after AKT2 inhibitor treatment compared to vehicle-treated cKO mice. $n=4$. Scale bars, 100 and $50 \mu \mathrm{m}$ (inset). $* P<0.05$ (one-way ANOVA and post hoc test). f Retina sections from 12-month-old Crybal ${ }^{\mathrm{f} / \mathrm{fl}}$ or Crybal cKO mice stained with glial fibrillary acidic protein (GFAP, red) and cellular retinaldehydebinding protein (CRALBP, green). Sections from cKO mice \pm intravitreal vehicle showed extensive staining of the Müller glial processes (cells staining for both CRALBP and GFAP, yellow indicating activation, arrows). This was significantly reduced after inhibitor treatment (asterisk). $n=4$. Scale bar, $50 \mu \mathrm{m}$. Adapted with permission from Ghosh et al. [96]

LCN-2 in pterygium could lead to dissolution of Bowman's layer and invasion of the retina by limbal basal epithelial cells [97]. Even though no studies have directly linked overexpression of LCN-2 with neovascularization in pterygium, this link has been proposed in the mouse model for corneal neovascularization. The authors speculate that the increased expression of LCN-2 after induction of neovascularization
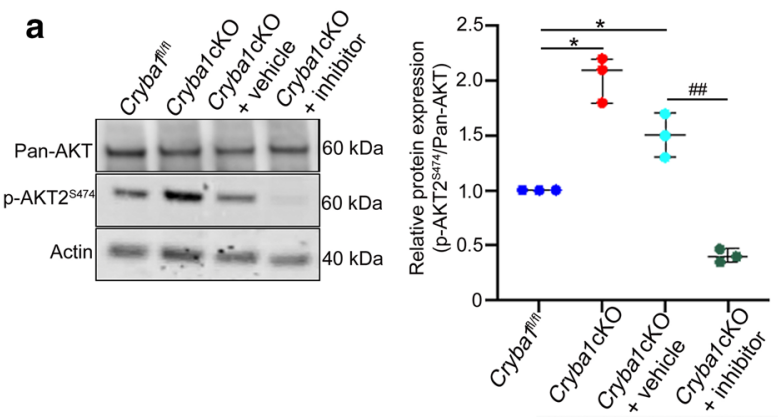

Fig. 14 An AKT2 inhibitor (CCT128930) reduces inflammation in aged Crybal cKO mouse retina. a Immunoblot and summary of densitometry showing a significant increase in the phosphorylation of AKT2 (p-AKT2 ${ }^{\mathrm{S} 474}$ ) in retinas from 1 year old Crybal cKO mice. The levels of p-AKT2 ${ }^{\mathrm{S} 474}$ in the Crybal cKO RPE decreased significantly following treatment with inhibitor (CCT128930, at a dose of $500 \mu \mathrm{M})$. Vehicle alone (2.5\% DMSO in PBS) had little effect. Additionally, levels of total AKT did not change in the samples. $n=3$.
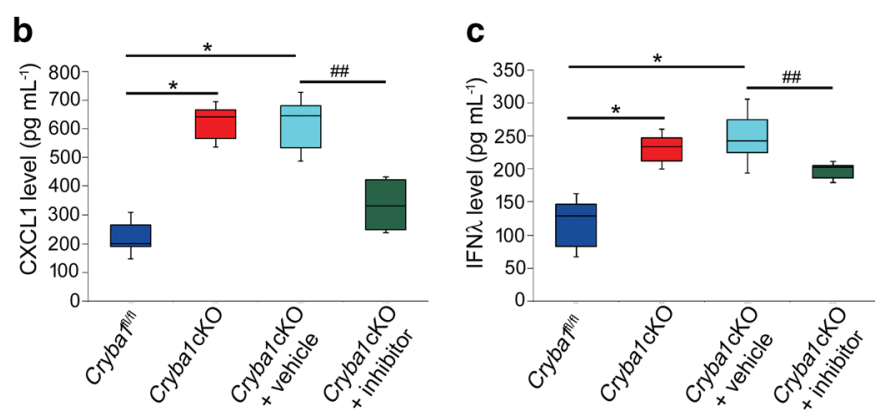

${ }^{*} P<0.05$ with respect to floxed control and ${ }^{\# \#} P<0.01$ with respect to vehicle-treated Crybal cKO. b, c ELISA assays show reduced levels $(\mathrm{pg} / \mathrm{ml})$ of CXCL1 and IFN $\lambda$ respectively, in the RPE choroid of AKT2 inhibitor-treated Crybal cKO mice, as compared to agematched vehicle and untreated Crybal cKO animals. $n=3 . * P<0.05$ with respect to floxed control and ${ }^{\# \#} P<0.01$ with respect to vehicletreated Crybal cKO. Reproduced with permission from Ghosh et al. [96] 

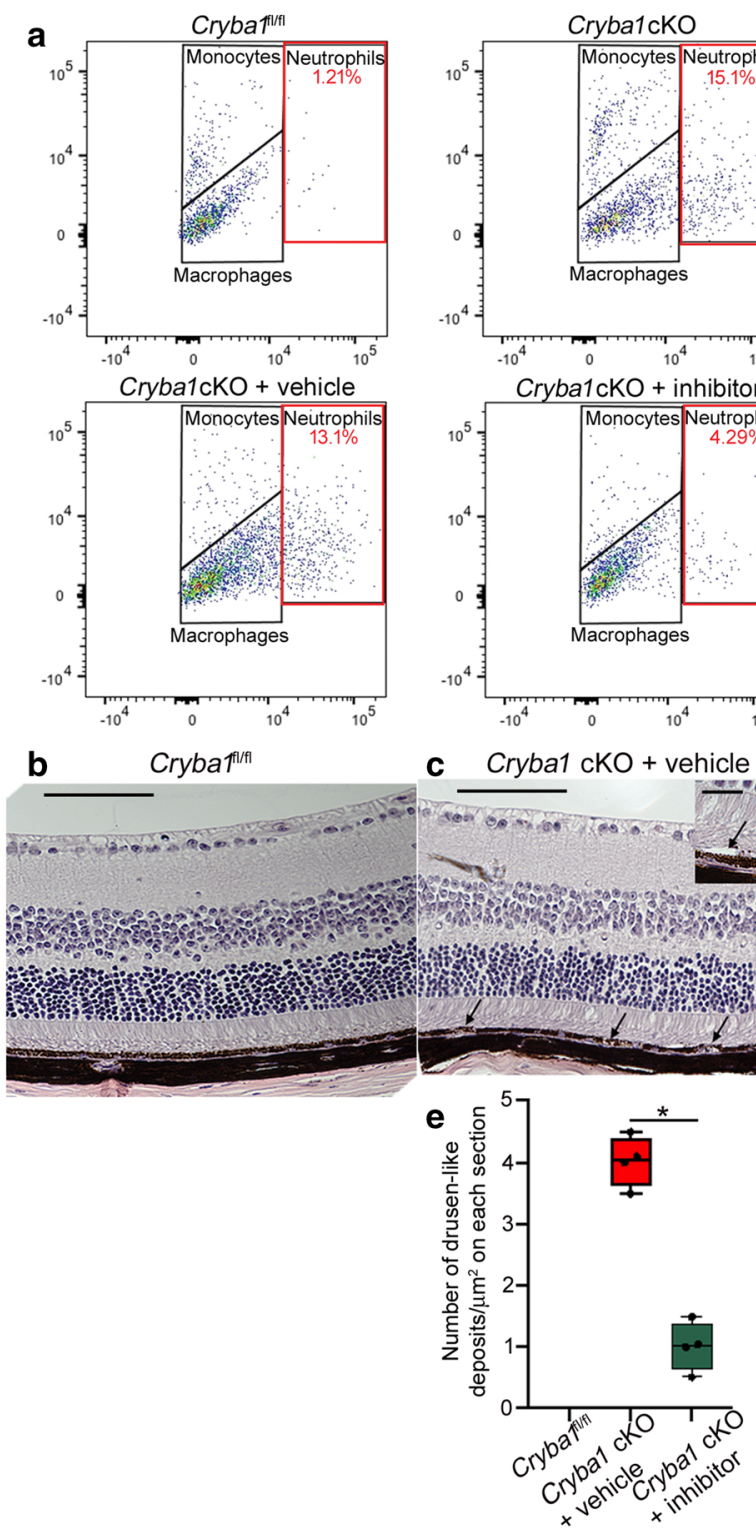
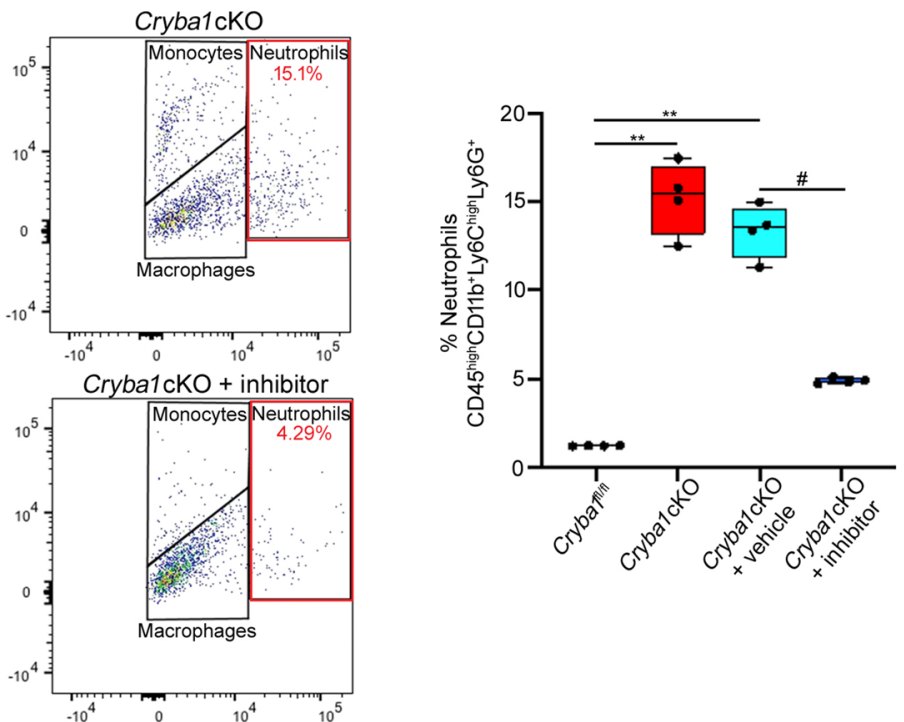

d Cryba $1 \mathrm{CKO}+$ inhibitor

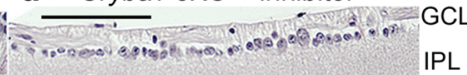

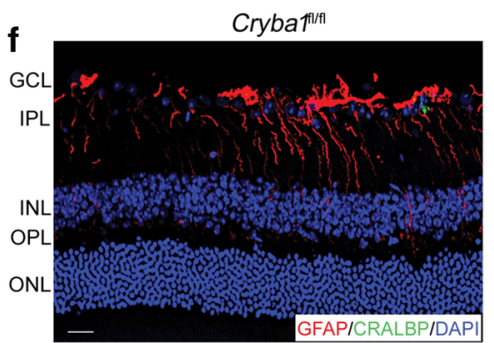

Cryba1 cKO + vehicle

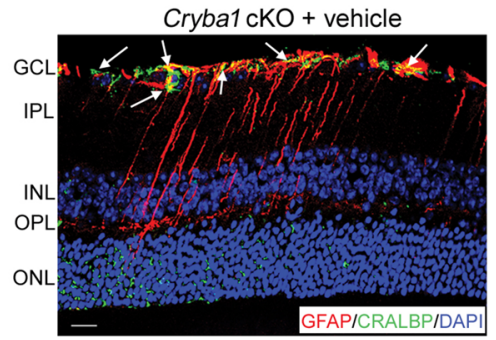

Cryba1 cKO

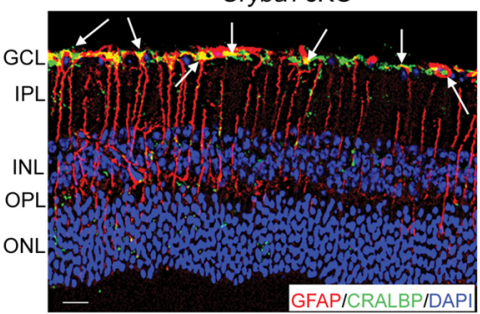

Cryba1 cKO + inhibitor

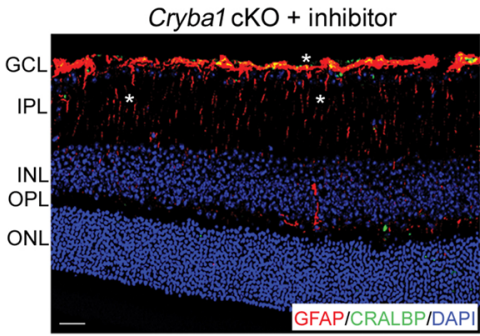


with alkali burns could induce VEGF through regulation of HIF- $1 \alpha$ [99]. Stabilization of MMP-9 by LCN-2 could also facilitate VEGF liberation thus promoting angiogenesis [99]. Interestingly, the interaction between LCN-2 and MMP-9 could also contribute to the TGF $\beta$-mediated epithelial-tomesenchymal transition of the lens epithelial cells following cataract surgery $[100,101]$.

While the majority of studies on the role of $\mathrm{LCN}-2$ in ocular health focus on intraocular inflammation, a few studies demonstrated that $\mathrm{LCN}-2$ is involved in a number of optic nerve disorders. For example, LCN-2 expression was increased $>80$ fold in the ganglion cells following optic nerve crush - a popular model for glaucoma and neuronal apoptosis due to axonal degeneration [102]. LCN-2 was also found to regulate inflammation in the optic nerve during the progression of optic neuritis [103]. Optic neuritis is frequently the first clinical manifestation of multiple sclerosis, and is characterized by acute self-limiting inflammation of the optic nerve associated with demyelination of the retinal ganglion cell axons and decreased visual acuity. Similar to intraocular inflammation, LCN-2 expression was found to be increased in the experimental autoimmune optic neuritis model; however, in this study, LCN-2 contributed to creation of a pro-inflammatory rather than an anti-inflammatory environment: $\mathrm{KO}$ of LCN-2 positively impacted the clinical prognosis. Demyelination, immune cell infiltration, activation of microglia, and astrocytes, as well as the production of cytokines and chemokines, were significantly reduced in the LCN-2 KO mice compared to controls. LCN-2 immunostaining co-localized with the astrocyte-specific marker glial fibrillary acidic protein (GFAP), suggesting that reactive astrocytes are the main sources of $\mathrm{LCN}-2$ in the inflamed optic nerves. The authors speculate that the lack of the classical blood-brain-barrier properties of the optic nerve (compared to the retina) may facilitate the recruitment of immune cells and development of inflammation [103].

Overall, LCN-2 is significantly overexpressed not only in AMD, but in a variety of ocular pathologies, involving different tissues, which makes it an attractive therapeutic target for future drug development.

\section{Targeting LCN-2 for therapeutic intervention in AMD: future prospects}

AMD is the leading cause of blindness in the elderly population and is classified as either early/dry or wet AMD. About $90 \%$ of patients with AMD have the dry form of the disease, for which there is no effective treatment available at the present time [104]. Therefore, understanding the molecular pathways involving AMD pathogenesis and establishing a treatment for dry AMD is of paramount importance.
Targeting LCN-2 has been previously employed for treating diseases other than AMD. Specifically, LCN-2 inhibition has been used as a therapy for metastatic cancers $[81,105]$. However, LCN-2 is not currently used for treatment of dry AMD. We have recently shown that LCN-2 expression was elevated in AMD retinae through activation of the AKT2dependent pathway and that inhibiting AKT2 specifically could decrease LCN-2 levels in the retina (Fig. 13) [92]. We have recently shown that specifically blocking AKT2 (using AKT2 inhibitor CCT128930) in RPE cells could successfully mitigate inflammation (Fig. 14), neutrophil infiltration into the retina, Müller cell activation, and assauge dry AMD-like phenotype (Fig. 15) in the Crybal cKO mice [96]. Therefore, inhibiting AKT2 will also likely contribute to alterations in other intracellular pathways because of its involvement in many diverse signaling cascades [106]. Our previous study has proved that STAT1 is essential in lcn2 gene activation, particularly during the acute to chronic inflammatory transition in AMD [92]. Taken together, we hypothesize that inhibiting specific signaling molecules like interferons (IFNs), which activate STAT1 [107, 108], particularly during AMD pathogenesis, could be beneficial in ameliorating LCN-2 activation. Moreover, targeting LCN-2 with specific neutralizing antibodies or by gene silencing could also be beneficial in establishing a therapeutic regime for delaying the progression of dry AMD.

In this review, we have discussed the importance of LCN-2 in ocular diseases, mainly in AMD, and identified molecular cascades involved in the activation of the protein, which could be targeted for therapeutic interventions in the future.

Acknowledgements This study was funded by National Eye Institute: EY019037-S (DS), RPB/IRRF Catalyst Award for Innovative Research Approaches for AMD (DS), BrightFocus Foundation, Jennifer Salvitti Davis Chair in Ophthalmology (DS), Research to Prevent Blindness (Ophthalmology, UPMC), NY

\section{References}

1. Flower DR (1994) The lipocalin protein family: a role in cell regulation. FEBS Lett 354:7-11

2. Flower DR (1996) The lipocalin protein family: structure and function. Biochem J 318:1-14

3. Flower DR, North AC, Attwood TK (1993) Structure and sequence relationships in the lipocalins and related proteins. Protein Sci 2:753-761

4. Flower DR, North AC, Sansom CE (2000) The lipocalin protein family: structural and sequence overview. Biochim Biophys Acta 1482:9-24

5. Ganfornina MD, Gutierrez G, Bastiani M, Sanchez D (2000) A phylogenetic analysis of the lipocalin protein family. Mol Biol Evol 17:114-126

6. Ahnstrom J, Faber K, Axler O, Dahlback B (2007) Hydrophobic ligand binding properties of the human lipocalin apolipoprotein M. J Lipid Res 48:1754-1762 
7. Dartt DA (2011) Tear lipocalin: structure and function. Ocul Surf 9:126-138

8. Bolignano D, Donato V, Coppolino G, Campo S, Buemi A, Lacquaniti A, Buemi M (2008) Neutrophil gelatinase-associated lipocalin (NGAL) as a marker of kidney damage. Am J Kidney Dis 52:595-605

9. Yang J, Bielenberg DR, Rodig SJ, Doiron R, Clifton MC, Kung AL, Strong RK, Zurakowski D, Moses MA (2009) Lipocalin 2 promotes breast cancer progression. Proc Natl Acad Sci USA 106:3913-3918

10. Kehrer JP (2010) Lipocalin-2: pro- or anti-apoptotic? Cell Biol Toxicol 26:83-89

11. Xu S, Venge P (2000) Lipocalins as biochemical markers of disease. Biochim Biophys Acta 1482:298-307

12. Bundgaard JR, Sengelov H, Borregaard N, Kjeldsen L (1994) Molecular cloning and expression of a cDNA encoding NGAL: a lipocalin expressed in human neutrophils. Biochem Biophys Res Commun 202:1468-1475

13. Kjeldsen L, Bainton DF, Sengelov H, Borregaard N (1993) Structural and functional heterogeneity among peroxidase-negative granules in human neutrophils: identification of a distinct gelatinase-containing granule subset by combined immunocytochemistry and subcellular fractionation. Blood 82:3183-3191

14. Kjeldsen L, Cowland JB, Borregaard N (2000) Human neutrophil gelatinase-associated lipocalin and homologous proteins in rat and mouse. Biochim Biophys Acta 1482:272-283

15. Kjeldsen L, Koch C, Arnljots K, Borregaard N (1996) Characterization of two ELISAs for NGAL, a newly described lipocalin in human neutrophils. J Immunol Methods 198:155-164

16. Asimakopoulou A, Weiskirchen S, Weiskirchen R (2016) Lipocalin 2 (LCN2) Expression in Hepatic Malfunction and Therapy. Front Physiol 7:430

17. Flower DR, North AC, Attwood TK (1991) Mouse oncogene protein $24 \mathrm{p} 3$ is a member of the lipocalin protein family. Biochem Biophys Res Commun 180:69-74

18. Hamilton RT, Nilsen-Hamilton M, Adams G (1985) Superinduction by cycloheximide of mitogen-induced secreted proteins produced by Balb/c 3T3 cells. J Cell Physiol 123:201-208

19. Rudd PM, Mattu TS, Masure S, Bratt T, Van den Steen PE, Wormald MR, Kuster B, Harvey DJ, Borregaard N, Van Damme J, Dwek RA, Opdenakker G (1999) Glycosylation of natural human neutrophil gelatinase B and neutrophil gelatinase B-associated lipocalin. Biochemistry 38:13937-13950

20. Axelsson L, Bergenfeldt M, Ohlsson K (1995) Studies of the release and turnover of a human neutrophil lipocalin. Scan J Clin Lab Investig 55:577-588

21. The Human Protein Atlas. https://www.proteinatlas.org/ENSG0 0000148346-LCN2/tissue. Accessed 25 June 2019.

22. Yang J, Moses MA (2009) Lipocalin 2: a multifaceted modulator of human cancer. Cell Cycle 8:2347-2352

23. Mallbris L, O'Brien KP, Hulthen A, Sandstedt B, Cowland JB, Borregaard N, Stahle-Backdahl M (2002) Neutrophil gelatinaseassociated lipocalin is a marker for dysregulated keratinocyte differentiation in human skin. Exp Dermatol 11:584-591

24. Aigner F, Maier HT, Schwelberger HG, Wallnöfer EA, Amberger A, Obrist P, Berger T, Mak TW, Maglione M, Margreiter R, Schneeberger S, Troppmair J (2007) Lipocalin-2 regulates the inflammatory response during ischemia and reperfusion of the transplanted heart. Am J Transpl 7:779-788

25. Borkham-Kamphorst E, Drews F, Weiskirchen R (2011) Induction of lipocalin-2 expression in acute and chronic experimental liver injury moderated by pro-inflammatory cytokines interleukin-1beta through nuclear factor-kappaB activation. Liver Int 31:656-665

26. Blaser J, Triebel S, Tschesche H (1995) A sandwich enzyme immunoassay for the determination of neutrophil lipocalin in body fluids. Clin Chim Acta 235:137-145
27. Devireddy LR, Gazin C, Zhu X, Green MR (2005) A cell-surface receptor for lipocalin $24 \mathrm{p} 3$ selectively mediates apoptosis and iron uptake. Cell 123:1293-1305

28. Richardson DR (2005) $24 \mathrm{p} 3$ and its receptor: dawn of a new iron age? Cell 123:1175-1177

29. Schmidt-Ott KM, Mori K, Li JY, Kalandadze A, Cohen DJ, Devarajan P, Barasch J (2007) Dual action of neutrophil gelatinase-associated lipocalin. J Am Soc Nephrol 18:407-413

30. Eller K, Schroll A, Banas M, Kirsch AH, Huber JM, Nairz M, Skvortsov S, Weiss G, Rosenkranz AR, Theurl I (2013) Lipocalin-2 expressed in innate immune cells is an endogenous inhibitor of inflammation in murine nephrotoxic serum nephritis. PLoS ONE 8:e67693

31. Jha MK, Jeon S, Jin M, Ock J, Kim JH, Lee WH, Suk K (2014) The pivotal role played by lipocalin-2 in chronic inflammatory pain. Exp Neurol 254:41-53

32. Cowland JB, Borregaard N (1997) Molecular characterization and pattern of tissue expression of the gene for neutrophil gelatinase-associated lipocalin from humans. Genomics 45:17-23

33. Lee S, Park JY, Lee WH, Kim H, Park HC, Mori K, Suk K (2009) Lipocalin-2 is an autocrine mediator of reactive astrocytosis. $\mathbf{J}$ Neurosci 29:234-249

34. Lee S, Lee J, Kim S, Park JY, Lee WH, Mori K, Kim SH, Kim IK, Suk K (2007) A dual role of lipocalin 2 in the apoptosis and deramification of activated microglia. J Immunol 179:3231-3241

35. Jeon S, Jha MK, Ock J, Seo J, Jin M, Cho H, Lee WH, Suk K (2013) Role of lipocalin-2-chemokine axis in the development of neuropathic pain following peripheral nerve injury. J Biol Chem 288:24116-24127

36. Kerjaschki D, Farquhar MG (1982) The pathogenic antigen of Heymann nephritis is a membrane glycoprotein of the renal proximal tubule brush border. Proc Natl Acad Sci USA 79:5557-5561

37. Li XC, Zhuo JL (2014) Mechanisms of AT1a receptor-mediated uptake of angiotensin II by proximal tubule cells: a novel role of the multiligand endocytic receptor megalin. Am J Physiol Renal Physiol 307:F222-233

38. Marino M, Pinchera A, McCluskey RT, Chiovato L (2001) Megalin in thyroid physiology and pathology. Thyroid 11:47-56

39. Marzolo MP, Farfan P (2011) New insights into the roles of megalin/LRP2 and the regulation of its functional expression. Biol Res 44:89-105

40. Peruchetti DB, Cheng J, Caruso-Neves C, Guggino WB (2014) Mis-regulation of mammalian target of rapamycin (mTOR) complexes induced by albuminuria in proximal tubules. J Biol Chem 289:16790-16801

41. Suzuki T, Yamaguchi H, Ogura J, Kobayashi M, Yamada T, Iseki K (2013) Megalin contributes to kidney accumulation and nephrotoxicity of colistin. Antimicrob Agents Chemother 57:6319-6324

42. Zheng G, Marino M, Zhao J, McCluskey RT (1998) Megalin (gp330): a putative endocytic receptor for thyroglobulin (Tg). Endocrinology 139:1462-1465

43. Christensen EI, Birn H (2001) Megalin and cubilin: synergistic endocytic receptors in renal proximal tubule. Am J Physiol Renal Physiol 280:F562-573

44. Assemat E, Chatelet F, Chandellier J, Commo F, Cases O, Verroust P, Kozyraki R (2005) Overlapping expression patterns of the multiligand endocytic receptors cubilin and megalin in the CNS, sensory organs and developing epithelia of the rodent embryo. Gene Expr Patterns 6:69-78

45. Fisher CE, Howie SE (2006) The role of megalin (LRP-2/Gp330) during development. Dev Biol 296:279-297

46. Lundgren S, Carling T, Hjalm G, Juhlin C, Rastad J, Pihlgren U, Rask L, Akerstrom G, Hellman P (1997) Tissue distribution of human gp330/megalin, a putative $\mathrm{Ca}(2+)$-sensing protein. $\mathbf{J}$ Histochem Cytochem 45:383-392 
47. Konig O, Ruttiger L, Muller M, Zimmermann U, Erdmann B, Kalbacher H, Gross M, Knipper M (2008) Estrogen and the inner ear: megalin knockout mice suffer progressive hearing loss. FASEB J 22:410-417

48. Mizuta K, Saito A, Watanabe T, Nagura M, Arakawa M, Shimizu F, Hoshino T (1999) Ultrastructural localization of megalin in the rat cochlear duct. Hear Res 129:83-91

49. Fitzgerald M, Nairn P, Bartlett CA, Chung RS, West AK, Beazley LD (2007) Metallothionein-IIA promotes neurite growth via the megalin receptor. Exp Brain Res 183:171-180

50. Ortega MC, Cases O, Merchan P, Kozyraki R, Clemente D, de Castro F (2012) Megalin mediates the influence of sonic hedgehog on oligodendrocyte precursor cell migration and proliferation during development. Glia 60:851-866

51. Goetz DH, Holmes MA, Borregaard N, Bluhm ME, Raymond KN, Strong RK (2002) The neutrophil lipocalin NGAL is a bacteriostatic agent that interferes with siderophore-mediated iron acquisition. Mol Cell 10:1033-1043

52. Bachman MA, Miller VL, Weiser JN (2009) Mucosal lipocalin 2 has pro-inflammatory and iron-sequestering effects in response to bacterial enterobactin. PLoS Pathog 5:e1000622

53. Nasioudis D, Witkin SS (2015) Neutrophil gelatinase-associated lipocalin and innate immune responses to bacterial infections. Med Microbiol Immunol 204:471-479

54. Venge P (2018) Human neutrophil lipocalin (HNL) as a biomarker of acute infections. Ups J Med Sci 123:1-8

55. Steigedal M, Marstad A, Haug M, Damås JK, Strong RK, Roberts PL, Himpsl SD, Stapleton A, Hooton TM, Mobley HL, Hawn TR, Flo TH (2014) Lipocalin 2 imparts selective pressure on bacterial growth in the bladder and is elevated in women with urinary tract infection. J Immunol 193:6081-6089

56. Yun BA, Yang EM, Kim CJ (2018) Plasma neutrophil gelatinaseassociated lipocalin as a predictor of renal parenchymal involvement in infants with febrile urinary tract infection: a preliminary study. Ann Lab Med 38:425-430

57. Karadag Z, Sehitoglu T, Cure MC, Rakici H, Ayvaz MA, Bedir R, Kizilkaya B, Şahin OZ, Cure E (2018) Helicobacter pylori can be related to carotid intima-media thickness, epicardial adipose tissue thickness and serum neutrophil gelatinase-associated lipocalin (NGAL) levels. Bratisl Lek Listy 119:302-307

58. Holden VI, Wright MS, Houle S, Collingwood A, Dozois CM, Adams MD, Bachman MA (2018) Iron acquisition and siderophore release by carbapenem-resistant sequence type $258 \mathrm{Kleb}$ siellapneumoniae. mSphere 3:e00125-18

59. Kim JW, Hong DY, Lee KR, Kim SY, Baek KJ, Park SO (2016) Usefulness of plasma neutrophil gelatinase-associated lipocalin concentration for predicting the severity and mortality of patients with community-acquired pneumonia. Clin Chim Acta 462:140-145

60. Reghunathan R, Jayapal M, Hsu LY, Chng HH, Tai D, Leung BP, Melendez AJ (2005) Expression profile of immune response genes in patients with severe acute respiratory syndrome. BMC Immunol 6:2

61. Morieri ML, Guardigni V, Sanz JM, Dalla Nora E, Soavi C, Zuliani G, Sighinolfi L, Passaro A (2018) Adipokines levels in HIV infected patients: lipocalin-2 and fatty acid binding protein- 4 as possible markers of HIV and antiretroviral therapyrelated adipose tissue inflammation. BMC Infect Dis 18:10

62. Fu Y, Gaelings L, Jalovaara P, Kakkola L, Kinnunen MT, Kallio-Kokko H, Valkonen M, Kantele A, Kainov DE (2016) Protein profiling of nasopharyngeal aspirates of hospitalized and outpatients revealed cytokines associated with severe influenza A(H1N1)pdm09 virus infections: a pilot study. Cytokine 86:10-14

63. Nairz M, Schroll A, Haschka D, Dichtl S, Sonnweber T, Theurl I, Theurl M, Lindner E, Demetz E, Aßhoff M, Bellmann-Weiler R,
Müller R, Gerner RR, Moschen AR, Baumgartner N, Moser PL, Talasz H, Tilg H, Fang FC, Weiss G (2015) Lipocalin-2 ensures host defense against Salmonellatyphimurium by controlling macrophage iron homeostasis and immune response. Eur J Immunol 45:3073-3086

64. Nairz M, Ferring-Appel D, Casarrubea D, Sonnweber T, Viatte L, Schroll A, Haschka D, Fang FC, Hentze MW, Weiss G, Galy B (2015) Iron regulatory proteins mediate host resistance to salmonella infection. Cell Host Microbe 18:254-261

65. Coorens M, Rao A, Gräfe SK, Unelius D, Lindforss U, Agerberth B, Mjösberg J, Bergman P (2019) Innate lymphoid cell type 3-derived interleukin-22 boosts lipocalin-2 production in intestinal epithelial cells via synergy between STAT3 and NF-кB. J Biol Chem 294:6027-6041

66. Warszawska JM, Gawish R, Sharif O, Sigel S, Doninger B, Lakovits K, Mesteri I, Nairz M, Boon L, Spiel A, Fuhrmann V, Strobl B, Müller M, Schenk P, Weiss G, Knapp S (2013) Lipocalin 2 deactivates macrophages and worsens pneumococcal pneumonia outcomes. J Clin Investig 123:3363-3372

67. Dahl SL, Woodworth JS, Lerche CJ, Cramer EP, Nielsen PR, Moser C, Thomsen AR, Borregaard N, Cowland JB (2018) Lipocalin-2 functions as inhibitor of innate resistance to Mycobacteriumtuberculosis. Front Immunol 9:2717

68. Srinivasan G, Aitken JD, Zhang B, Carvalho FA, Chassaing B, Shashidharamurthy R, Borregaard N, Jones DP, Gewirtz AT, Vijay-Kumar M (2002) Lipocalin 2 deficiency dysregulates iron homeostasis and exacerbates endotoxin-induced sepsis. J Immunol 189:1911-1919

69. Berger T, Togawa A, Duncan GS, Elia AJ, You-Ten A, Wakeham A, Fong HE, Cheung CC, Mak TW (2006) Lipocalin 2-deficient mice exhibit increased sensitivity to Escherichia coli infection but not to ischemia-reperfusion injury. Proc Natl Acad Sci USA 103:1834-1839

70. Schroll A, Eller K, Feistritzer C, Nairz M, Sonnweber T, Moser PA, Rosenkranz AR, Theurl I, Weiss G (2012) Lipocalin-2 ameliorates granulocyte functionality. Eur J Immunol 42:3346-3357

71. Kundu P, Ling TW, Korecka A, Li Y, D’Arienzo R, Bunte RM, Berger T, Arulampalam V, Chambon P, Mak TW, Wahli W, Pettersson S (2014) Absence of intestinal PPAR $\gamma$ aggravates acute infectious colitis in mice through a lipocalin-2-dependent pathway. PLoS Pathog 10:e1003887

72. Suk K (2012) Proteomic analysis of glioma chemoresistance. Curr Neuropharmacol 10:72-79

73. Zheng LT, Lee S, Yin GN, Mori K, Suk K (2009) Down-regulation of lipocalin 2 contributes to chemoresistance in glioblastoma cells. J Neurochem 111:1238-1251

74. Berard JL, Zarruk JG, Arbour N, Prat A, Yong VW, Jacques FH, Akira S, David S (2012) Lipocalin 2 is a novel immune mediator of experimental autoimmune encephalomyelitis pathogenesis and is modulated in multiple sclerosis. Glia 60:1145-1159

75. Chang CF, Cho S, Wang J (2014) (-)-Epicatechin protects hemorrhagic brain via synergistic Nrf2 pathways. Ann Clin Transl Neurol 1:258-271

76. Howe CL, Kaptzan T, Magana SM, Ayers-Ringler JR, LaFranceCorey RG, Lucchinetti CF (2014) Neuromyelitis optica IgG stimulates an immunological response in rat astrocyte cultures. Glia 62:692-708

77. Bi F, Huang C, Tong J, Qiu G, Huang B, Wu Q, Li F, Xu Z, Bowser R, Xia XG, Zhou H (2013) Reactive astrocytes secrete $1 \mathrm{cn} 2$ to promote neuron death. Pro Natl Acad Sci USA 110:4069-4074

78. Naude PJ, Nyakas C, Eiden LE, Ait-Ali D, van der Heide R, Engelborghs S, Luiten PG, De Deyn PP, den Boer JA, Eisel UL (2012) Lipocalin 2: novel component of proinflammatory signaling in Alzheimer's disease. FASEB J 26:2811-2823 
79. Shashidharamurthy R, Machiah D, Aitken JD, Putty K, Srinivasan G, Chassaing B, Parkos CA, Selvaraj P, Vijay-Kumar M (2013) Differential role of lipocalin 2 during immune complexmediated acute and chronic inflammation in mice. Arthritis Rheumatol 65:1064-1073

80. Nam Y, Kim JH, Seo M, Kim JH, Jin M, Jeon S, Seo JW, Lee WH, Bing SJ, Jee Y, Lee WK, Park DH, Kook H, Suk K (2014) Lipocalin-2 protein deficiency ameliorates experimental autoimmune encephalomyelitis: the pathogenic role of lipocalin-2 in the central nervous system and peripheral lymphoid tissues. J Biol Chem 289:16773-16789

81. Hu C, Yang K, Li M, Huang W, Zhang F, Wang H (2018) Lipocalin 2: a potential therapeutic target for breast cancer metastasis. Onco Targets Ther 11:8099-8106

82. Xu B, Jin DY, Lou WH, Wang DS (2013) Lipocalin-2 is associated with a good prognosis and reversing epithelial-to-mesenchymal transition in pancreatic cancer. World J Surg 37:1892-1900

83. Mannelqvist M, Stefansson IM, Wik E, Kusonmano K, Raeder MB, Øyan AM, Kalland KH, Moses MA, Salvesen HB, Akslen LA (2012) Lipocalin 2 expression is associated with aggressive features of endometrial cancer. BMC Cancer 12:169

84. Wang Y, Lam KS, Kraegen EW, Sweeney G, Zhang J, Tso AW, Chow WS, Wat NM, Xu JY, Hoo RL, Xu A (2007) Lipocalin-2 is an inflammatory marker closely associated with obesity, insulin resistance, and hyperglycemia in humans. Clin Chem 53:34-41

85. Elkhidir AE, Eltaher HB, Mohamed AO (2017) Association of lipocalin-2 level, glycemic status and obesity in type 2 diabetes mellitus. BMC Res Notes 10:285

86. Makhezer N, Ben Khemis M, Liu D, Khichane Y, Marzaioli V, Tlili A, Mojallali M, Pintard C, Letteron P, Hurtado-Nedelec M, El-Benna J, Marie JC, Sannier A, Pelletier AL, Dang PM (2019) NOX1-derived ROS drive the expression of Lipocalin-2 in colonic epithelial cells in inflammatory conditions. Mucosal Immunol 12:117-131

87. Viau A, El Karoui K, Laouari D, Burtin M, Nguyen C, Mori K, Pillebout E, Berger T, Mak TW, Knebelmann B, Friedlander G, Barasch J, Terzi F (2010) Lipocalin 2 is essential for chronic kidney disease progression in mice and humans. J Clin Investig 120:4065-4076

88. Yoshikawa K, Iwasa M, Eguchi A, Kojima S, Yoshizawa N, Tempaku M, Sugimoto R, Yamamoto N, Sugimoto K, Kobayashi Y, Hasegawa H, Takei Y (2017) Neutrophil gelatinase-associated lipocalin level is a prognostic factor for survival in rat and human chronic liver diseases. Hepatol Commun 1:946-956

89. Parmar T, Parmar VM, Arai E, Sahu B, Perusek L, Maeda A (2016) Acute stress responses are early molecular events of retinal degeneration in $\mathrm{Abca}^{-/-} \mathrm{Rdh}^{-/-}$mice after light exposure. Investig Ophthalmol Vis Sci 57:3257-3267

90. Tang W, Ma J, Gu R, Ding X, Lei B, Wang X, Zhuang H, Xu G (2018) Lipocalin 2 suppresses ocular inflammation by inhibiting the activation of NF- $\kappa \beta$ pathway in endotoxin-induced uveitis. Cell Physiol Biochem 46:375-388

91. Valapala M, Edwards M, Hose S, Grebe R, Bhutto IA, Cano M, Berger T, Mak TW, Wawrousek E, Handa JT, Lutty GA, Zigler SJ, Sinha D (2014) Increased Lipocalin-2 in the retinal pigment epithelium of Crybal cKO mice is associated with a chronic inflammatory response. Aging Cell 13:1091-1094

92. Ghosh S, Shang P, Yazdankhah M, Bhutto I, Hose S, Montezuma SR, Luo T, Chattopadhyay S, Qian J, Lutty GA, Ferrington DA, Zigler JS, Sinha D (2017) Activating the AKT2-nuclear factor$\kappa \mathrm{B}$-lipocalin-2 axis elicits an inflammatory response in agerelated macular degeneration. J Pathol 241:583-588

93. Tang W, Ma J, Gu R, Lei B, Ding X, Xu G (2018) Light-induced lipocalin 2 facilitates cellular apoptosis by positively regulating reactive oxygen species/Bim signaling in retinal degeneration. Investig Ophthalmol Vis Sci 59:6014-6025
94. Parmar T, Parmar VM, Perusek L, Georges A, Takahashi M, Crabb JW, Maeda A (2018) Lipocalin 2 plays an important role in regulating inflammation in retinal degeneration. J Immunol 200:3128-3141

95. Shang P, Valapala M, Grebe R, Hose S, Ghosh S, Bhutto IA, Handa JT, Lutty GA, Lu L, Wan J, Qian J, Sergeev Y, Puertollano R, Zigler JS Jr, Xu GT, Sinha D (2017) The amino acid transporter SLC36A4 regulates the amino acid pool in retinal pigmented epithelial cells and mediates the mechanistic target of rapamycin, complex 1 signaling. Aging Cell 16:349-359

96. Ghosh S, Padmanabhan A, Vaidya T, Watson AM, Bhutto IA, Hose S, Shang P, Stepicheva N, Yazdankhah M, Weiss J, Das M, Gopikrishna S, Aishwarya YN, Berger T, Mak TW, Xia S, Qian J, Lutty GA, Jayagopal A, Zigler JS Jr, Sethu S, Handa JT, Watkins SC, Ghosh A, Sinha D (2019) Neutrophils homing into the retina trigger pathology in early age-related macular degeneration. Commun Biol 2:348

97. Hofmaier F, Hauck SM, Amann B, Degroote RL, Deeg CA (2011) Changes in matrix metalloproteinase network in a spontaneous autoimmune uveitis model. Investig Ophthalmol Vis Sci 52:2314-2320

98. John-Aryankalayil M, Dushku N, Jaworski CJ, Cox CA, Schultz G, Smith JA, Ramsey KE, Stephan DA, Freedman KA, Reid TW, Carper DA (2006) Microarray and protein analysis of human pterygium. Mol Vis 12:55-64

99. Shen M, Tao Y, Feng Y, Liu X, Yuan F, Zhou H (2016) Quantitative proteomic analysis of mice corneal tissues reveals angiogenesis-related proteins involved in corneal neovascularization. Biochim Biophys Acta 1864:787-793

100. Jiang J, Shihan MH, Wang Y, Duncan MK (2018) Lens epithelial cells initiate an inflammatory response following cataract surgery. Investig Ophthalmol Vis Sci 59:4986-4997

101. Korol A, Pino G, Dwivedi D, Robertson JV, Deschamps PA, West-Mays JA (2014) Matrix metalloproteinase-9-null mice are resistant to TGF- $\beta$-induced anterior subcapsular cataract formation. Am J Pathol 184:2001-2012

102. Ueno S, Yoneshige A, Koriyama Y, Hagiyama M, Shimomura Y, Ito A (2018) Early gene expression profile in retinal ganglion cell layer after optic nerve crush in mice. Investig Ophthalmol Vis Sci 59:370-380

103. Chun BY, Kim JH, Nam Y, Huh MI, Han S, Suk K (2015) Pathological involvement of astrocyte-derived lipocalin-2 in the demyelinating optic neuritis. Investig Ophthalmol Vis Sci 56:3691-3698

104. ALL ABOUT VISION. https://www.allaboutvision.com/condi tions/amd.htm. Accessed on 25 June 2019.

105. Lin CW, Yang WE, Lee WJ, Hua KT, Hsieh FK, Hsiao M, Chen CC, Chow JM, Chen MK, Yang SF, Chien MH (2016) Lipocalin 2 prevents oral cancer metastasis through carbonic anhydrase IX inhibition and is associated with favourable prognosis. Carcinogenesis 37:712-722

106. Manning BD, Toker A (2017) AKT/PKB signaling: navigating the network. Cell 169:381-405

107. Dussurget O, Bierne H, Cossart P (2014) The bacterial pathogen Listeria monocytogenes and the interferon family: type I, type II and type III interferons. Front Cell Infect Microbiol 4:50

108. Zhao P, Elks CM, Stephens JM (2014) The induction of lipocalin-2 protein expression in vivo and in vitro. $\mathrm{J}$ Biol Chem 289:5960-5969

Publisher's Note Springer Nature remains neutral with regard to jurisdictional claims in published maps and institutional affiliations. 